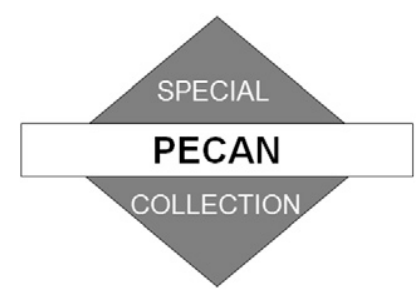

\title{
Mesoscale Ascent in Nocturnal Low-Level Jets
}

\author{
ALAN SHAPIRO \\ School of Meteorology, and Center for Analysis and Prediction of Storms, \\ University of Oklahoma, Norman, Oklahoma \\ EVGENI FEDOROVICH \\ School of Meteorology, University of Oklahoma, Norman, Oklahoma \\ JoshuA G. GebAuer \\ School of Meteorology, and Cooperative Institute for Mesoscale Meteorological Studies, \\ University of Oklahoma, Norman, Oklahoma
}

(Manuscript received 18 September 2017, in final form 12 February 2018)

\begin{abstract}
A theory for gentle but persistent mesoscale ascent in the lower troposphere is developed in which the vertical motion arises as an inertia-gravity wave response to the sudden decrease of turbulent mixing in a horizontally heterogeneous convective boundary layer (CBL). The zone of ascent is centered on the local maximum of a laterally varying buoyancy field (warm tongue in the CBL). The shutdown also triggers a Blackadar-type inertial oscillation and associated low-level jet (LLJ). These nocturnal motions are studied analytically using the linearized two-dimensional Boussinesq equations of motion, thermal energy, and mass conservation for an inviscid stably stratified fluid, with the initial state described by a zero-order jump model of a CBL. The vertical velocity revealed by the analytical solution increases with the amplitude of the buoyancy variation, CBL depth, and wavenumber of the buoyancy variation (larger vertical velocity for smaller-scale variations). Stable stratification in the free atmosphere has a lid effect, with a larger buoyancy frequency associated with a smaller vertical velocity. For the parameter values typical of the southern Great Plains warm season, the peak vertical velocity is $\sim 3-10 \mathrm{~cm} \mathrm{~s}^{-1}$, with parcels rising $\sim 0.3-1 \mathrm{~km}$ over the $\sim 6-8$-h duration of the ascent phase. Data from the 2015 Plains Elevated Convection at Night (PECAN) field project were used as a qualitative check on the hypothesis that the same mechanism that triggers nocturnal LLJs from CBLs can induce gentle but persistent ascent in the presence of a warm tongue.
\end{abstract}

\section{Introduction}

It has long been recognized that warm season precipitation over the central United States exhibits a nocturnal maximum (Kincer 1916; Bleeker and Andre 1951; Means 1952; Pitchford and London 1962; Wallace 1975; Easterling and Robinson 1985; Riley et al. 1987; Dai et al. 1999; Carbone et al. 2002; Carbone and Tuttle 2008). This rainfall is beneficial for agriculture, but it is also associated with lightning, flooding, and other weather hazards (Crysler et al. 1982; Orville and Henderson 1986; Maddox et al. 1979, 1986; Fritsch et al. 1986; Jirak and Cotton 2007). Operational

Corresponding author: Alan Shapiro, ashapiro@ou.edu numerical weather prediction and global circulation models have little skill in forecasting nocturnal precipitation in this region (Davis et al. 2003; Clark et al. 2007; Lee et al. 2008; Surcel et al. 2010; Song et al. 2013).

Nocturnal convection over the central United States often develops within an eastward-propagating envelope of successively dissipating and regenerating mesoscale convective systems (MCSs) originating from afternoon thunderstorms over the Rocky Mountains (Maddox 1983; Augustine and Caracena 1994; Dai et al. 1999; Carbone et al. 2002; Davis et al. 2003; Carbone and Tuttle 2008). However, it can also develop without any apparent connection to ongoing or preexisting convection (Wilson and Roberts 2006; Reif and Bluestein 2017; 
Geerts et al. 2017). During the International $\mathrm{H}_{2} \mathrm{O}$ Project (IHOP_2002) over the southern Great Plains of the United States, more than half of the 26 storm complexes that entered the study area dissipated within the domain, while 112 cases of in situ convection initiation (CI) occurred (Wilson and Roberts 2006). Approximately half of these CI cases were triggered without the presence of a nearby surface convergence boundary and occurred mostly at night. Many of these elevated nocturnal CI cases were associated with regions of synoptic or mesoscale convergence in the 900-600-hPa layer apparent in Rapid Update Cycle (RUC) wind analyses. In a 20-yr climatology of warm season nocturnal CI over the central and southern Great Plains, Reif and Bluestein (2017) found that $24 \%$ of the nocturnal CI episodes occurred without a nearby surface boundary. Nearly one-half of these no-boundary (NB) $\mathrm{CI}$ episodes were of a linear storm type, the majority of which had a preferred north-south orientation, the same preference exhibited by nocturnal low-level jets (LLJs) over the Great Plains (e.g., Hoecker 1963; Bonner 1968; Bonner et al. 1968; Mitchell et al. 1995; Whiteman et al. 1997; Song et al. 2005). Reif and Bluestein (2017) found a common association of LLJs with all of the nocturnal CI modes, but noted that the association was closest with the NB mode.

Regions of low- or midlevel horizontal convergence in the nocturnal environment can promote or initiate convection by deepening the moist layer and lifting air parcels toward their level of free convection (Weckwerth and Parsons 2006; Wilson and Roberts 2006). Most recently, Trier et al. (2017) suggested that weak but persistent mesoscale ascent might lead to the formation of moist absolutely unstable layers (MAULs), from which convection can develop. Elucidating the mechanisms of nocturnal CI can be challenging because of the subtleties and complexities of the many candidate phenomena and the fact that many of these phenomena occur simultaneously. Among the plausible mechanisms for CI are convergence and ascent associated with deeptropospheric gravity waves (e.g., Uccelini 1975; Koch et al. 1988; Fovell et al. 2006; Marsham and Parker 2006); cold fronts, density currents, and drylines (e.g., Charba 1974; Wilson and Schreiber 1986; Mahoney 1988; Weckwerth and Wakimoto 1992; Hane et al. 1993; Ziegler and Rasmussen 1998; Weiss and Bluestein 2002; Geerts et al. 2006; Weckwerth et al. 2008); inland or "vegetation" breezes (e.g., Sun and Ogura 1979; Mahfouf et al. 1987; Segal and Arritt 1992; Mahrt et al. 1994; Lynn et al. 1998; McPherson 2007; Drobinski and Dubos 2009); bores, solitons, and other shallow trapped gravity waves (e.g., Carbone et al. 1990; Karyampudi et al. 1995; Koch et al. 1988; Koch and Clark 1999; Coleman and Knupp 2011; Marsham et al. 2011; Haghi et al. 2017); and nocturnal LLJs (e.g., Means 1952; Blackadar 1959; Pitchford and London 1962; Bonner 1966; Bonner et al. 1968; Paegle and Rasch 1973; Paegle and McLawhorn 1973; Paegle 1978; Maddox 1983; Maddox and Grice 1983; Wallace 1975; Astling et al. 1985; Trier and Parsons 1993; Augustine and Caracena 1994; Higgins et al. 1997; Arritt et al. 1997; Walters and Winkler 2001; Tuttle and Davis 2006; Trier et al. 2006, 2014, 2017; Carbone and Tuttle 2008; French and Parker 2010; Pu and Dickinson 2014; Reif and Bluestein 2017). Some of the latter LLJ studies also suggest that there are multiple modes of LLJ-associated convection: nocturnal convection over the Great Plains is most often initiated or maintained by convergence at the jet terminus (northern terminus in the typically southerly jet) or at the intersection of a jet with a front or other surface boundary, but is also often observed along a lateral flank of a jet.

In this study we explore a boundary layer mechanism for inducing gentle but persistent mesoscale ${ }^{1}$ ascent in warm season LLJs. We do not address CI per se but consider a mechanism that produces net vertical parcel displacements of magnitudes that may facilitate CI. Our work is motivated by the close associations between LLJs and nocturnal convection over the Great Plains described in many of the above-noted LLJ papers and also documented for other regions worldwide (e.g., Velasco and Fritsch 1987; Stensrud 1996; Liebmann et al. 2004; Salio et al. 2007; Monaghan et al. 2010; Wang et al. 2013; Chen and Tomassini 2015). The roles of ascent in a decelerating flow north of an LLJ wind maximum (in a southerly LLJ), or along or north of the intersection of an LLJ with a cold front, are more or less clear, but the mechanisms that force ascent on a lateral flank of an LLJ are still not well understood. In this regard, we believe that the recent Pu and Dickinson (2014) explanation for such a mechanism is not wholly satisfactory. In a study of vertical motions in Great Plains LLJs using a North American Regional Reanalysis (NARR) June-July climatology, Pu and Dickinson (2014) suggest that after midnight, as the jet weakens, the vertical vorticity should increase (decrease) to the east (west) of the jet core, ${ }^{2}$ and that vertical motions "are developed to balance" those tendencies. However, a balance

\footnotetext{
${ }^{1}$ We consider hydrostatic but highly ageostrophic motions on the meso- $\alpha$ scale $(200-2000 \mathrm{~km})$.

${ }^{2}$ A kinematic explanation is given for these vorticity tendencies. If the vorticity $\zeta$ is dominated by the lateral shear of the southerly wind, then $\zeta$ is negative (positive) to the east (west) of the jet core. As the jet weakens, $\zeta$ decreases in magnitude on both flanks of the jet. Accordingly, $\zeta$ increases where it is negative (eastern flank) and decreases where it is positive (western flank).
} 
concept may not be appropriate for Great Plains LLJs (no justification was given), and the authors' vertical vorticity budget analysis merely indicates that diurnal changes in the vertical vorticity over the scale of their analysis domain are largely due to the stretching of Earth vorticity, regardless of the convergence mechanism.

We use an analytical model to explore how weak but persistent convergent motions can arise from the release of the frictional constraint in a horizontally inhomogeneous convective boundary layer (CBL) at sunset. To illustrate the concept in its most basic form and gain some insights into the nature and scale of the kinds of inhomogeneities that may be relevant, we work with an idealized zeroorder jump model of the CBL for the initial state and a simple inviscid model for the nocturnal motion. We consider, in turn, lateral variations in the free-atmosphere geostrophic wind and CBL buoyancy. The nocturnal state following the shutdown of mixing is modeled as a twodimensional (2D) inviscid flow of a stably stratified fluid. In this scenario, flow convergence cannot occur at the terminus of a jet (there is no terminus) but is parallel to the jet axis. The shutdown of mixing that triggers the convergence in our theory is the same mechanism that triggers an inertial oscillation (IO) that manifests as an LLJ in Blackadar's (1957) pioneering theory. ${ }^{3}$ Both modes of motion occur in our model, but because the initial wind field is independent of height in the CBL (well-mixed assumption in the zero-order model), the nocturnal IO-LLJ is slab-like.

In section 2 we present the governing equations. Solutions are obtained for initial states characterized by lateral variations in free-atmosphere geostrophic wind (section 2) and CBL buoyancy (section 3). As the latter variations are found to be much more effective in generating vertical motions, we focus on the relevance of buoyancy forcing in three CI cases from the Plains Elevated Convection at Night (PECAN; Geerts et al. 2017) field project (section 4). A summary and concluding remarks follow in section 5 .

\section{Laterally varying free-atmosphere geostrophic wind}

\section{a. Late afternoon profiles of wind and buoyancy}

Our initial $(t=0)$ state is based on a zero-order jump model of a deep late afternoon CBL with overlying free

\footnotetext{
${ }^{3}$ For further discussions on boundary layer-induced IOs, see Buajitti and Blackadar (1957), Thorpe and Guymer (1977), Baas et al. (2009), Van de Wiel et al. (2010), Shapiro and Fedorovich (2010), and many others.
}

atmosphere (Fedorovich 1995), schematized in Fig. 1. In the zero-order model, the bulk of the CBL is idealized as a layer of strong turbulent mixing (mixed layer) throughout which momentum and potential temperature are independent of height $z$. The top of the CBL coincides with a capping inversion of vanishing thickness at $z=H$ across which the wind and potential temperature jump in value. For vertical integrals up to $z=H$ in which a distinction between the top or bottom of the inversion is important, we denote the upper limit of integration by $\mathrm{H}^{+}$if the inversion is included and by $\mathrm{H}^{-}$if the inversion is excluded.

We consider the free atmosphere above the CBL to be barotropic (free-atmosphere geostrophic wind is independent of $z$ ), hydrostatic, and in a geostrophic balance. The free-atmosphere geostrophic wind is aligned with the $y$ axis (pointing north) ${ }^{4}$ and varies in the east-west $x$ direction as

$$
v_{G}(x)=\bar{v}_{G}+A \sin k x,
$$

where $A$ is the amplitude of the variation, $k$ is the wavenumber, and $\bar{v}_{G}$ is the horizontal mean value. Without loss of generality, we take $k$ and $A$ to be positive.

The free-atmosphere potential temperature $\theta_{e}(z)$ increases linearly with height, so the free-atmosphere buoyancy (Brunt-Väisälä) frequency $N$, defined through

$$
N^{2} \equiv \frac{g}{\theta_{r}} \frac{d \theta_{e}}{d z}
$$

is constant. Here $g$ is the acceleration due to gravity and $\theta_{r}(=300 \mathrm{~K})$ is a constant reference value of potential temperature.

We assume the $y$-component wind $v_{0}$ varies as a piecewise constant function of $z$, with a discontinuity at the capping inversion. Within the CBL, $v_{0}$ is a constant fraction $\varepsilon(<1)$ of the free-atmosphere geostrophic wind, while above the CBL, $v_{0}$ is equal to the freeatmosphere geostrophic wind:

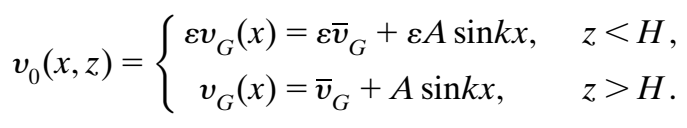

For later use, we note that (2.3) implies

$$
\frac{\partial^{2} v_{0}}{\partial z \partial x}=(1-\varepsilon) A k \delta(z-H) \cos k x
$$

\footnotetext{
${ }^{4}$ This free-atmosphere geostrophic wind is southerly if $v_{G}>0$ and northerly if $v_{G}<0$. However, our analysis can be extended to free-atmosphere geostrophic winds aligned with any direction (and varying perpendicular to that direction) by rotating the coordinate axes.
} 


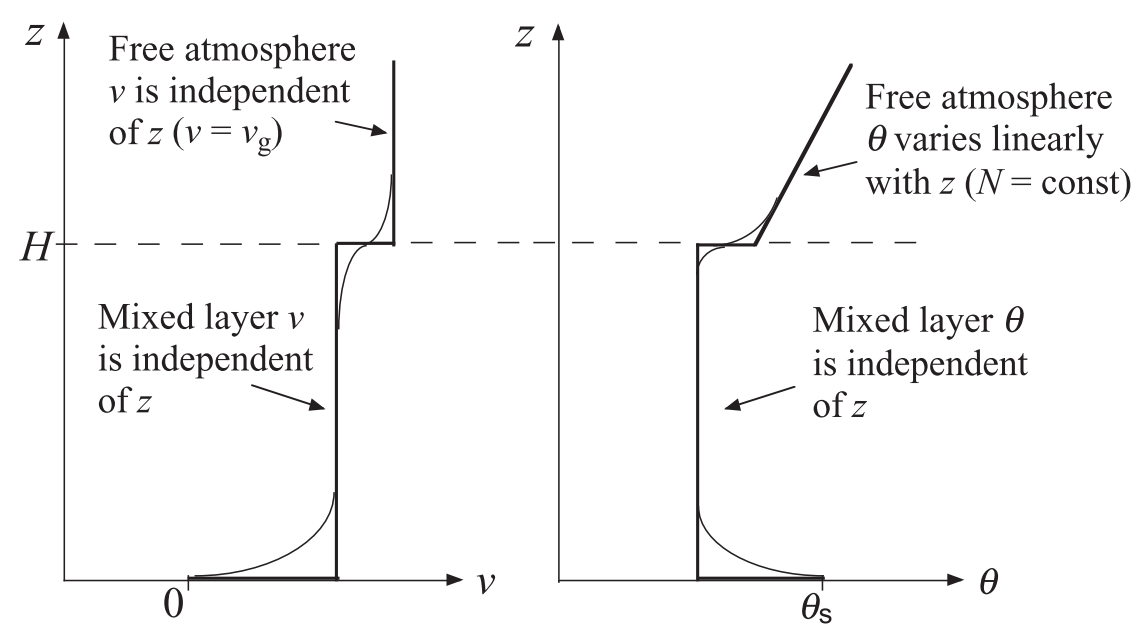

FIG. 1. Schematic of wind and potential temperature profiles in the CBL (thin lines) and the corresponding profiles in a zero-order model of the CBL (bold lines). Variables in the zeroorder model jump in value across a capping inversion at $z=H$. Adapted from Fedorovich (1995).

where $\delta(z-H)$ is the Dirac delta function. The $x$-velocity component $u_{0}$ is set to zero everywhere, that is, we neglect the frictional-stress-mediated (Ekman) cross-isobar flow. In CBLs this component is often much smaller than the component in the direction of the geostrophic wind (Arya 1977; van Ulden and Holtslag 1985). The vertical velocity $w_{0}$ is set to zero everywhere.

We consider the potential temperature $\theta_{0}$ to be independent of $x$ and $z$ within the CBL, to jump in value across the capping inversion, and to follow the freeatmosphere profile $\theta_{e}$ above the CBL:

$$
\theta_{0}(z)= \begin{cases}\theta_{e}(H)-\Delta \theta, & z<H \\ \theta_{e}(z), & z>H\end{cases}
$$

Here $\Delta \theta(>0)$ is the potential temperature jump (inversion strength). Integration of (2.2) yields

$$
\theta_{e}(z)=\theta_{e}(H)+\frac{\theta_{r}}{g} N^{2}(z-H)
$$

The $\theta_{e}(z)$ profile defined by (2.6) coincides with the actual potential temperature profile in the free atmosphere $(z>H)$. However, we use this same (2.6) - for all $z$ - to define the potential temperature for the reference atmosphere. This reference profile appears in (2.5) and in the definition of buoyancy,

$$
b \equiv \frac{g}{\theta_{r}}\left[\theta-\theta_{e}(z)\right]
$$

Applying (2.5) and (2.6) in (2.7) yields the late afternoon buoyancy profile as

$$
b_{0}(z)= \begin{cases}-\frac{g}{\theta_{r}} \Delta \theta+N^{2}(H-z), & z<H, \\ 0, & z>H .\end{cases}
$$

The kinematic pressure perturbation $\Pi\left[\equiv(p-P) / \rho_{r}\right.$, where $p$ is pressure, $P=P\left(x^{*}, z\right)$ is the reference pressure profile at a fixed $x$ location $x^{*}($ so $\partial P / \partial x=0)$, and $\rho_{r}$ is a constant value of density] satisfies the hydrostatic equation in the initial state $\left(\partial \Pi_{0} / \partial z=b_{0}\right)$ and in the postsunset motion $(\partial \Pi / \partial z=b)$. Since $b_{0}$ is independent of $x, \partial \Pi_{0} / \partial z$ is independent of $x$. Equivalently, $\partial \Pi_{0} / \partial x$ is independent of $z$. We therefore determine $\partial \Pi_{0} / \partial x$ at any height from its distribution in the free atmosphere, which we consider to be in the geostrophic balance, $0=-\partial \Pi_{0} / \partial x+f v_{G}(x)$, where the Coriolis parameter $f$ is constant. In view of this balance and (2.1), the integrated hydrostatic equation yields

$\Pi_{0}(x, z)=f \bar{v}_{G} x-\frac{f A}{k} \cos k x+\int_{0}^{z} b_{0}\left(z^{\prime}\right) d z^{\prime}+$ const.

\section{b. Postsunset evolution for the inhomogeneous $v_{0}$-forced problem}

We investigate the atmospheric response to the release of the frictional constraint at sunset using the $2 \mathrm{D}$ linearized Boussinesq equations of motion, thermal energy, and mass conservation for an inviscid stably stratified fluid on an $f$ plane:

$$
\begin{aligned}
& \frac{\partial u}{\partial t}=-\frac{\partial \Pi}{\partial x}+f v, \\
& \frac{\partial v}{\partial t}=-f u,
\end{aligned}
$$




$$
\begin{aligned}
0 & =-\frac{\partial \Pi}{\partial z}+b, \\
\frac{\partial b}{\partial t} & =-w N^{2}, \quad \text { and } \\
\frac{\partial u}{\partial x}+\frac{\partial w}{\partial z} & =0
\end{aligned}
$$

In view of (2.3), (2.9), and (2.10), the time-dependent part of $u$ has $\sin k x$ and horizontally uniform components. Equation (2.11) then shows that the time-dependent part of $v$ also has $\sin k x$ and horizontally uniform components, while (2.14) shows that $w$ varies in $x$ as $\cos k x$. Equation (2.13) then shows that the time-dependent part of $b$ varies in $x$ as $\cos k x$, in which case (2.12) [or (2.10)] shows that the timedependent part of $\Pi$ also varies as $\cos k x$. We thus write

$$
\begin{aligned}
v(x, z, t) & =v_{0}(x, z)+v_{m}(z, t)+v_{k}(z, t) \sin k x, \\
u(x, z, t) & =u_{m}(z, t)+u_{k}(z, t) \sin k x, \\
w(x, z, t) & =w_{k}(z, t) \cos k x, \\
b(x, z, t) & =b_{0}(z)+b_{k}(z, t) \cos k x, \quad \text { and } \\
\Pi(x, z, t) & =\Pi_{0}(x, z)+\Pi_{k}(z, t) \cos k x,
\end{aligned}
$$

where a subscript $m$ denotes an association with a horizontally uniform but time dependent motion, and a subscript 0 denotes the initial (late afternoon) state of a variable, as defined in section $2 \mathrm{a}$. Note that $w_{k}$ represents the $w$ profile at the $x$ location of peak strength, that is, where $\cos k x=1$. Since the initial states of $u, v, w, b$, and $\Pi$ appear as the 0 subscript variables in $(2.15 \mathrm{a})-(2.15 \mathrm{e})$, the $m$ and $k$ subscript variables are initially zero:

$$
\begin{aligned}
& u_{m}(z, 0)=v_{m}(z, 0)=0 \text { and } \\
& v_{k}(z, 0)=u_{k}(z, 0)=w_{k}(z, 0)=b_{k}(z, 0)=0 .
\end{aligned}
$$

When (2.15a)-(2.15e), (2.3), (2.8), and (2.9) are applied in (2.10)-(2.14), which are then averaged in $x$ over one wavelength $\lambda(=2 \pi / k)$, the only surviving terms involve the horizontally uniform time-dependent variables, which satisfy

$$
\begin{aligned}
& \frac{\partial u_{m}}{\partial t}=f v_{m}+f\left\{\begin{array}{ll}
(\varepsilon-1) \bar{v}_{G}, & z<H, \\
0, & z>H
\end{array}\right. \text { and } \\
& \frac{\partial v_{m}}{\partial t}=-f u_{m},
\end{aligned}
$$

and the late afternoon buoyancy and perturbation pressure terms, which satisfy the hydrostatic equation. The solution of (2.17) and (2.18) subject to (2.16a) is

$$
u_{m}=\left\{\begin{array}{ll}
-(1-\varepsilon) \bar{v}_{G} \sin f t, & z<H, \\
0, & z>H
\end{array} \quad\right. \text { and }
$$

$$
v_{m}= \begin{cases}(1-\varepsilon) \bar{v}_{G}(1-\cos f t), & z<H \\ 0, & z>H\end{cases}
$$

The sum of this (horizontally homogeneous) solution and the horizontally homogeneous part of the initial state is a Blackadar-type IO. We will refer to this motion as the homogeneous jet. The peak wind speed in the homogeneous jet occurs at time $t=\pi / f$, when the ageostrophic wind aligns with the free-atmosphere geostrophic wind (southerly in this case). This maximum homogeneous jet speed is the sum of the peak $v_{m}$ value of $2(1-\varepsilon) \bar{v}_{G}$ and the initial $\left(v_{0}\right)$ contribution $\varepsilon \bar{v}_{G}$. In the extreme (unrealistic) case where friction has brought the late afternoon southerly wind component in the mixed layer to zero $(\varepsilon=0)$, the peak wind speed would be twice the freeatmosphere geostrophic wind $2 \bar{v}_{G}$. For more realistic $\varepsilon$, the peak speed would be much less than this bound. For example, for $\varepsilon=0.7$ the peak speed is $2(1-0.7) \bar{v}_{G}+$ $0.7 \bar{v}_{G}=1.3 \bar{v}_{G}$, which is still supergeostrophic, but only exceeds the geostrophic value by $30 \%$.

We now turn to the laterally variable part of the flow and the associated vertical motion. Taking $\partial / \partial z(2.10)-$ $\partial / \partial x(2.12)$ yields an equation for the production of $y$-component vorticity $(\partial u / \partial z-\partial w / \partial x \approx \partial u / \partial z)$,

$$
\frac{\partial}{\partial t}\left(\frac{\partial u}{\partial z}\right)=f \frac{\partial v}{\partial z}-\frac{\partial b}{\partial x} .
$$

Taking $\partial / \partial t$ of (2.21) and using (2.11) and (2.13) to eliminate the tendencies of $v$ and $b$ yields

$$
\frac{\partial^{2}}{\partial t^{2}}\left(\frac{\partial u}{\partial z}\right)=-f^{2} \frac{\partial u}{\partial z}+N^{2} \frac{\partial w}{\partial x}
$$

Taking $\partial / \partial x$ of (2.22) followed by the use of (2.14) to eliminate $u$ yields a single equation for $w$,

$$
\left(\frac{\partial^{2}}{\partial t^{2}}+f^{2}\right) \frac{\partial^{2} w}{\partial z^{2}}+N^{2} \frac{\partial^{2} w}{\partial x^{2}}=0 .
$$

Equation (2.23) is a well-known wave equation for motions in a hydrostatic inertia-gravity wave regime (e.g., Gill 1982, p. 260; Lin 2007, p. 47). It admits free oscillations of the form $w=W \exp [i(k x+m z-\omega t)]$, where $W$ is the amplitude, $m$ is the vertical wavenumber, and the frequency $\omega$ satisfies the dispersion relation $\omega^{2}=f^{2}+N^{2} k^{2} / m^{2}$. Since the vertical component of the group velocity is $c_{g z}=\partial \omega / \partial m=-N^{2} k^{2} /\left(\omega m^{3}\right)$, upward energy propagation $\left(c_{g z}>0\right)$ requires that $\omega$ and $m$ are of opposite sign, in which case the phase propagation has a downward component. The time scales in this regime are about an order of magnitude smaller than the time scales in quasigeostrophic motions. 
Applying (2.15c) in (2.23) yields

$$
\left(\frac{\partial^{2}}{\partial t^{2}}+f^{2}\right) \frac{\partial^{2} w_{k}}{\partial z^{2}}-k^{2} N^{2} w_{k}=0 .
$$

We solve (2.24) using the method of Laplace transforms (e.g., Doetsch 1961). Multiplying (2.24) by $e^{-s t}$, where $s$ is a complex frequency, and integrating the resulting equation over time yields

$$
\left(s^{2}+f^{2}\right) \frac{d^{2} \hat{w}}{d z^{2}}-k^{2} N^{2} \hat{w}=\Phi(z),
$$

where $\hat{w}(z) \equiv \int_{0}^{\infty} e^{-s t} w_{k}(z, t) d t$ is the Laplace transform of $w_{k}$ and

$$
\left.\Phi(z) \equiv s \frac{\partial^{2} w_{k}}{\partial z^{2}}\right|_{t=0}+\left.\frac{\partial}{\partial t}\left(\frac{\partial^{2} w_{k}}{\partial z^{2}}\right)\right|_{t=0} .
$$

In view of (2.16b), the $s \partial^{2} w_{k} /\left.\partial z^{2}\right|_{t=0}$ term in (2.26) is zero. Taking $\partial / \partial x$ of (2.21) at $t=0$ and then using (2.14) to eliminate $u$ in favor of $w$ yields the tendency term in (2.26) as

$$
\left(\frac{\partial}{\partial t} \frac{\partial^{2} w}{\partial z^{2}}\right)_{t=0}=-f \frac{\partial^{2} v_{0}}{\partial z \partial x}+\frac{\partial^{2} b_{0}}{\partial x^{2}} .
$$

Evaluating this tendency term using (2.4) and (2.8), and applying it in (2.26), we obtain $\Phi$ as

$$
\Phi(z)=-f A k(1-\varepsilon) \delta(z-H) .
$$

We solve (2.25) subject to the impermeability condition,

$$
\hat{w}(0)=0,
$$

and the remote condition,

$$
\lim _{z \rightarrow \infty} \hat{w}=0
$$

The method of variation of parameters yields the general solution of (2.25):

$$
\begin{aligned}
\hat{w}= & E e^{k N z / \sqrt{s^{2}+f^{2}}}+F e^{-k N z / \sqrt{s^{2}+f^{2}}} \\
& +\frac{1}{2 k N \sqrt{s^{2}+f^{2}}} \int_{0}^{z} \Phi\left(z^{\prime}\right)\left[e^{k N\left(z-z^{\prime}\right) / \sqrt{s^{2}+f^{2}}}\right. \\
& \left.-e^{-k N\left(z-z^{\prime}\right) / \sqrt{s^{2}+f^{2}}}\right] d z^{\prime} .
\end{aligned}
$$

Applying (2.28) in (2.31) yields

$$
\hat{w}= \begin{cases}E e^{k N z / \sqrt{s^{2}+f^{2}}}+F e^{-k N z / \sqrt{s^{2}+f^{2}}}, & z<H, \\ E e^{k N z / \sqrt{s^{2}+f^{2}}}+F e^{-k N z / \sqrt{s^{2}+f^{2}}}-\frac{f A(1-\varepsilon)}{2 N \sqrt{s^{2}+f^{2}}\left[e^{k N(z-H) / \sqrt{s^{2}+f^{2}}}-e^{-k N(z-H) / \sqrt{s^{2}+f^{2}}}\right],} \quad z>H\end{cases}
$$

Applying (2.29) and (2.30) in (2.32) yields

$$
F=-E, \quad E=\frac{f A(1-\varepsilon)}{2 N} \frac{e^{-k N H / \sqrt{s^{2}+f^{2}}}}{\sqrt{s^{2}+f^{2}}} .
$$

We then obtain $\hat{w}$ (for all $z$ ) as

$$
\hat{w}=\frac{f A(1-\varepsilon)}{2 N}\left(\frac{e^{-\alpha / \sqrt{s^{2}+f^{2}}}}{\sqrt{s^{2}+f^{2}}}-\frac{e^{-\beta / \sqrt{s^{2}+f^{2}}}}{\sqrt{s^{2}+f^{2}}}\right),
$$

where we have used $z-H=-|z-H|$ for $z<H$, $z-H=|z-H|$ for $z>H$, and defined

$$
\alpha \equiv k N|z-H|, \quad \beta \equiv k N(z+H) .
$$

Combining (5) on p. 227 with (40) on p. 245 of Erdélyi et al. (1954), yields the inverse Laplace transform $L^{-1}$ of $\left(s^{2}+f^{2}\right)^{-1 / 2} \exp \left[-c\left(s^{2}+f^{2}\right)^{-1 / 2}\right]$ for $c>0$ in the form:

$$
\begin{aligned}
& L^{-1}\left(\frac{e^{-c / \sqrt{s^{2}+f^{2}}}}{\sqrt{s^{2}+f^{2}}}\right)=J_{0}(2 \sqrt{c t}) \\
& \quad-f \int_{0}^{t} J_{1}\left(f t^{\prime}\right) J_{0}\left[2 \sqrt{c}\left(t^{2}-t^{2}\right)^{1 / 4}\right] d t^{\prime},
\end{aligned}
$$

where $J_{n}(\phi)(n=0,1)$ are Bessel functions of the first kind (appendix A). Using (2.36), we obtain the inverse transform of (2.34) as

$$
\begin{aligned}
w_{k}= & \frac{f A(1-\varepsilon)}{2 N}\left[J_{0}(2 \sqrt{\alpha t})-J_{0}(2 \sqrt{\beta t})\right] \\
& -\frac{f^{2} A(1-\varepsilon)}{2 N} \int_{0}^{t} J_{1}\left(f t^{\prime}\right)\left\{J_{0}\left[2 \sqrt{\alpha}\left(t^{2}-t^{\prime 2}\right)^{1 / 4}\right]\right. \\
& \left.-J_{0}\left[2 \sqrt{\beta}\left(t^{2}-t^{\prime 2}\right)^{1 / 4}\right]\right\} d t^{\prime} .
\end{aligned}
$$

Inspection of (2.37) shows that $w_{k}$ is proportional to $A(1-\varepsilon)$, which is the amplitude of the step change in the laterally varying part of $v_{0}$. The dependences of $w_{k}$ 


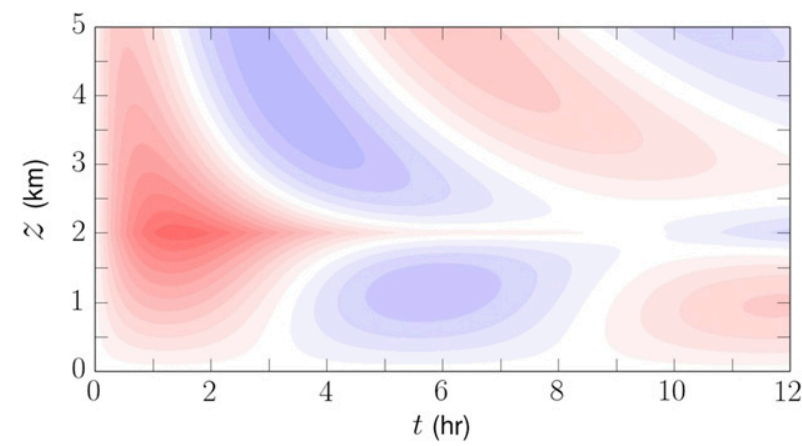

$\begin{array}{lllllllll}-1.00 & -0.75 & -0.50 & -0.25 & 0.00 & 0.25 & 0.50 & 0.75 & 1.00\end{array}$

FIG. 2. Time-height plot of $w_{k}\left(\mathrm{~cm} \mathrm{~s}^{-1}\right)$ from (2.37) for the $v_{0}$-forced problem with $\lambda=400 \mathrm{~km}, \varepsilon=0.8, H=2 \mathrm{~km}$, and $A=$ $5 \mathrm{~m} \mathrm{~s}^{-1}$

on $k, N$, and $f$ are not as clear since those parameters appear in the arguments of the Bessel functions. However, numerical evaluation of (2.37) (appendix A) reveals that $w_{k}$ increases with increasing $k$, increasing $f$, and decreasing $N$.

Numerical evaluation of (2.37) for a wide range of parameters shows that the vertical motion is quite weak, with peak $w_{k}$ values generally less than $1 \mathrm{~cm} \mathrm{~s}^{-1}$. An example is shown in Fig. 2 for the case where $f=8.6 \times 10^{-5} \mathrm{~s}^{-1}, N=0.010 \mathrm{~s}^{-1}, H=2000 \mathrm{~m}, \varepsilon=0.8$, $\bar{v}_{G}=10 \mathrm{~m} \mathrm{~s}^{-1}, A=5 \mathrm{~m} \mathrm{~s}^{-1}$, and $\lambda=400 \mathrm{~km}(k \approx 1.57 \times$ $\left.10^{-5} \mathrm{~m}^{-1}\right)$; here $w_{k}$ barely reaches $0.5 \mathrm{~cm} \mathrm{~s}^{-1}$. Horizontal variations in the free-atmosphere geostrophic wind are ineffective in generating ascent.

\section{Laterally varying CBL buoyancy}

\section{a. Late afternoon profiles of wind and buoyancy}

Our initial state is again described by a zero-order jump model of a CBL with a barotropic free atmosphere above it. However, now the potential temperature is considered to vary laterally within the CBL while the free-atmosphere geostrophic wind is horizontally homogeneous. Again we set $u_{0}$ and $w_{0}$ to zero. The southerly wind $v_{0}$ is again a piecewise constant function of height with jump across the capping inversion, but now without an $x$ dependence:

$$
v_{0}(z)= \begin{cases}\varepsilon \bar{v}_{G}, & z<H \\ \bar{v}_{G}, & z>H\end{cases}
$$

The laterally varying potential temperature $\theta_{0}$ is well mixed vertically within the CBL, jumps in value $\Delta \theta$ across the capping inversion, and follows the freeatmosphere profile of $\theta_{e}$ above the CBL. The inversion strength and $\theta_{0}$ profile are specified as

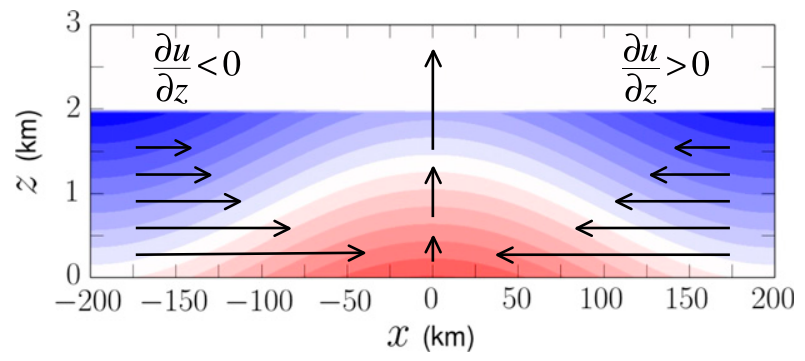

FIG. 3. Schematic of buoyancy $b$ and ascent in a warm tongue. The magnitude of $b$ increases with shading intensity; red indicates positive $b$, blue indicates negative $b$. The baroclinic term in the horizontal vorticity equation $[(2.21)]$ generates negative $\partial u / \partial z$ where $\partial b / \partial x>0$, and positive $\partial u / \partial z$ where $\partial b / \partial x<0$. The associated horizontal convergence and ascent are largest over the buoyancy maximum. In the Northern Hemisphere, the Coriolis force can be expected to gradually deflect the flow northward east of this maximum and southward west of this maximum.

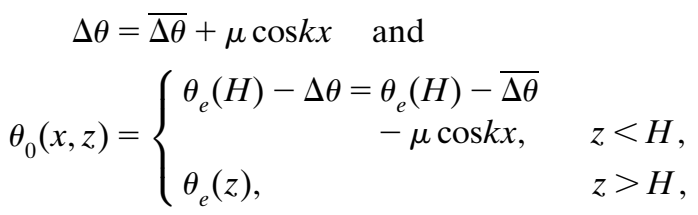

where $\mu$ is the amplitude of the potential temperature variation (a negative value of $\mu$ corresponds to a warm tongue centered on $x=0$ ), and $\overline{\Delta \theta}$ is the horizontal mean of $\Delta \theta$. We can specify $\mu$ in terms of the inversion strength maximum $\Delta \theta_{\max }$ and minimum $\Delta \theta_{\min }$ as $\mu=\left(\Delta \theta_{\max }-\Delta \theta_{\min }\right) / 2$. For the top of the CBL to be statically stable $(\Delta \theta>0), \mu$ and $\overline{\Delta \theta}$ must be prescribed such that $|\mu|<\overline{\Delta \theta}$. The $\cos k x$ dependence chosen for $\theta_{0}$ allows the phase relations in $(2.15 \mathrm{a})-(2.15 \mathrm{e})$ to apply (with minor modifications), so we can reuse much of the mathematical development from section 2 .

Applying (3.3) and (2.6) in (2.7) yields the buoyancy as

$b_{0}(x, z)= \begin{cases}-\frac{g}{\theta_{r}}(\overline{\Delta \theta}+\mu \cos k x)+N^{2}(H-z), & z<H, \\ 0, & z>H .\end{cases}$

A schematic that depicts this buoyancy field, the baroclinic generation of horizontal vorticity, and the ascent realized after the shutdown of turbulence (i.e., when the horizontal vorticity is no longer mixed out) is shown in Fig. 3.

Integrating the hydrostatic equation with respect to $z$ using $b_{0}$ from (3.4), and determining the resulting function of integration using the free-atmosphere geostrophic balance with constant geostrophic wind $\bar{v}_{G}$, we obtain $\Pi_{0}$ as 


$$
\Pi_{0}(x, z)= \begin{cases}f \bar{v}_{G} x-\frac{g}{\theta_{r}}(\overline{\Delta \theta}+\mu \cos k x)(z-H)-\frac{1}{2} N^{2}(H-z)^{2}+\text { const, } & z<H \\ f \bar{v}_{G} x+\text { const }, & z>H\end{cases}
$$

\section{b. Postsunset evolution for the inhomogeneous $b_{0}$-forced problem}

The phase relations in $(2.15 \mathrm{a})-(2.15 \mathrm{e})$ from the previous $v_{0}$-forced problem apply to this $b_{0}$-forced problem, though with (2.15a) and (2.15d) considered in the slightly modified forms,

$$
\begin{aligned}
& v(x, z, t)=v_{0}(z)+v_{m}(z, t)+v_{k}(z, t) \sin k x \quad \text { and } \\
& b(x, z, t)=b_{0}(x, z)+b_{k}(z, t) \cos k x .
\end{aligned}
$$

When (2.10)-(2.14) are averaged over one wavelength, using (3.6a), (3.6b), (2.15b), (2.15c), and (2.15e) with the initial profiles in (3.1), (3.4), and (3.5), we again find that $u_{m}$ and $v_{m}$ satisfy (2.17) and (2.18) and have the same solution as in (2.19) and (2.20). Moreover, since $v_{0}$ is the same as the homogeneous part of $v_{0}$ in the $v_{0}$-forced problem, the homogeneous jets in the two problems are identical.

We now turn to the solution for $w_{k}$. An expression for $\Phi(z)$ follows from (2.26), (2.27), (3.1), and (3.4) as

$$
\Phi(z)= \begin{cases}\frac{g}{\theta_{r}} \mu k^{2}, & z<H \\ 0, & z>H\end{cases}
$$

Applying (3.7) in (2.31) yields

$$
\hat{w}=\left\{\begin{array}{rlrl}
E e^{k N z / \sqrt{s^{2}+f^{2}}}+F e^{-k N z / \sqrt{s^{2}+f^{2}}}-\frac{g \mu}{2 \theta_{r} N^{2}}\left(2-e^{k N z / \sqrt{s^{2}+f^{2}}}-e^{-k N z / \sqrt{s^{2}+f^{2}}}\right), & & z<H, \\
E e^{k N z / \sqrt{s^{2}+f^{2}}}+F e^{-k N z / \sqrt{s^{2}+f^{2}}}-\frac{g \mu}{2 \theta_{r} N^{2}}\left[e^{k N(z-H) / \sqrt{s^{2}+f^{2}}}-e^{k N z / \sqrt{s^{2}+f^{2}}}\right. & \\
\left.+e^{-k N(z-H) / \sqrt{s^{2}+f^{2}}}-e^{-k N z / \sqrt{s^{2}+f^{2}}}\right], & z>H .
\end{array}\right.
$$

Application of (2.29) and (2.30) in (3.8) produces

With these values, (3.8) becomes

$$
F=-E, \quad E=\frac{g \mu}{2 \theta_{r} N^{2}}\left(e^{-k N H / \sqrt{s^{2}+f^{2}}}-1\right) .
$$

$$
\hat{w}=\frac{g \mu}{2 \theta_{r} N^{2}} \begin{cases}{\left[e^{k N(z-H) / \sqrt{s^{2}+f^{2}}}-e^{-k N(z+H) / \sqrt{s^{2}+f^{2}}}+2 e^{-k N z / \sqrt{s^{2}+f^{2}}}-2\right],} & z<H, \\ {\left[-e^{-k N(z+H) / \sqrt{s^{2}+f^{2}}}-e^{-k N(z-H) / \sqrt{s^{2}+f^{2}}}+2 e^{-k N z / \sqrt{s^{2}+f^{2}}}\right],} & z>H,\end{cases}
$$

which may be converted into a single form appropriate for all $z$ :

$$
\begin{aligned}
\hat{w}= & \frac{g \mu}{2 \theta_{r} N^{2}}\left[\operatorname{sgn}(z-H)\left(1-e^{-\alpha / \sqrt{s^{2}+f^{2}}}\right)\right. \\
& \left.+\left(1-e^{-\beta / \sqrt{s^{2}+f^{2}}}\right)-2\left(1-e^{-k N z / \sqrt{s^{2}+f^{2}}}\right)\right] .
\end{aligned}
$$

Here $\operatorname{sgn}(z-H)$ is the unit sign function (of $z-H$ ), and $\alpha$ and $\beta$ are defined in (2.35).

Combining (5) on p. 227 with (36) on p. 245 of Erdélyi et al. (1954), we obtain the inverse transform $L^{-1}$ of $1-\exp \left[-c\left(s^{2}+f^{2}\right)^{-1 / 2}\right]$ for $c>0$ :

$$
L^{-1}\left(1-e^{-c l \sqrt{s^{2}+f^{2}}}\right)=\frac{\sqrt{c}}{\sqrt{t}} J_{1}(2 \sqrt{c t})-f \sqrt{c} \int_{0}^{t} \frac{J_{1}\left(f t^{\prime}\right) J_{1}\left[2 \sqrt{c}\left(t^{2}-t^{\prime 2}\right)^{1 / 4}\right]}{\left(t^{2}-t^{\prime 2}\right)^{1 / 4}} d t^{\prime} .
$$


Using (3.12), we evaluate the inverse transform of

(3.11) as

$$
\begin{aligned}
w_{k}= & \frac{g \mu}{2 \theta_{r} N^{2}} \operatorname{sgn}(z-H)\left\{\frac{\sqrt{\alpha}}{\sqrt{t}} J_{1}(2 \sqrt{\alpha t})-f \sqrt{\alpha} \int_{0}^{t} \frac{J_{1}\left(f t^{\prime}\right) J_{1}\left[2 \sqrt{\alpha}\left(t^{2}-t^{\prime 2}\right)^{1 / 4}\right]}{\left(t^{2}-t^{\prime 2}\right)^{1 / 4}} d t^{\prime}\right\} \\
& +\frac{g \mu}{2 \theta_{r} N^{2}}\left\{\frac{\sqrt{\beta}}{\sqrt{t}} J_{1}(2 \sqrt{\beta t})-f \sqrt{\beta} \int_{0}^{t} \frac{J_{1}\left(f t^{\prime}\right) J_{1}\left[2 \sqrt{\beta}\left(t^{2}-t^{\prime 2}\right)^{1 / 4}\right]}{\left(t^{2}-t^{\prime 2}\right)^{1 / 4}} d t^{\prime}\right\} \\
& -\frac{g \mu}{\theta_{r} N^{2}}\left\{\frac{\sqrt{k N z}}{\sqrt{t}} J_{1}(2 \sqrt{k N z t})-f \sqrt{k N z} \int_{0}^{t} \frac{J_{1}\left(f t^{\prime}\right) J_{1}\left[2 \sqrt{k N z}\left(t^{2}-t^{\prime 2}\right)^{1 / 4}\right]}{\left(t^{2}-t^{\prime 2}\right)^{1 / 4}} d t^{\prime}\right\}
\end{aligned}
$$

To bypass computational difficulties arising from the singularities of $t^{-1 / 2}$ and $\left(t^{2}-t^{\prime 2}\right)^{-1 / 4}$ in (3.13), we rewrite all Bessel functions having $\sqrt{t}$ or $\left(t^{2}-t^{2}\right)^{1 / 4}$ in their arguments using (A.5), obtaining:

$$
\begin{aligned}
w_{k}= & \frac{\Gamma}{2}\left(\frac{z}{H}-1\right)\left[J_{0}(2 \sqrt{\alpha t})+J_{2}(2 \sqrt{\alpha t})\right]+\frac{\Gamma}{2}\left(\frac{z}{H}+1\right)\left[J_{0}(2 \sqrt{\beta t})+J_{2}(2 \sqrt{\beta t})\right]-\Gamma \frac{z}{H}\left[J_{0}(2 \sqrt{k N z t})+J_{2}(2 \sqrt{k N z t})\right] \\
& -\frac{\Gamma}{2}\left(\frac{z}{H}-1\right) f \int_{0}^{t} J_{1}\left(f t^{\prime}\right)\left\{J_{0}\left[2 \sqrt{\alpha}\left(t^{2}-t^{\prime 2}\right)^{1 / 4}\right]+J_{2}\left[2 \sqrt{\alpha}\left(t^{2}-t^{\prime 2}\right)^{1 / 4}\right]\right\} d t^{\prime}-\frac{\Gamma}{2}\left(\frac{z}{H}+1\right) f \int_{0}^{t} J_{1}\left(f t^{\prime}\right)\left\{J_{0}\left[2 \sqrt{\beta}\left(t^{2}-t^{\prime 2}\right)^{1 / 4}\right]\right. \\
& \left.+J_{2}\left[2 \sqrt{\beta}\left(t^{2}-t^{\prime 2}\right)^{1 / 4}\right]\right\} d t^{\prime}+\Gamma \frac{z}{H} f \int_{0}^{t} J_{1}\left(f t^{\prime}\right)\left\{J_{0}\left[2 \sqrt{k N z}\left(t^{2}-t^{\prime 2}\right)^{1 / 4}\right]+J_{2}\left[2 \sqrt{k N z}\left(t^{2}-t^{\prime 2}\right)^{1 / 4}\right]\right\} d t^{\prime}
\end{aligned}
$$

where

$$
\Gamma \equiv \frac{g k H \mu}{\theta_{r} N}
$$

and we have used the fact that $\alpha \operatorname{sgn}(z-H)=$ $k N|z-H| \operatorname{sgn}(z-H)=k N(z-H)$ for all $z$.

Since $\mu$ acts in (3.14) only through $\Gamma$ [via (3.15)], $w_{k}$ is directly proportional to $\mu$. Less clear is how $w_{k}$ varies with $H, k$, and $N$, since those parameters appear in the arguments of the Bessel functions as well as in $\Gamma$. However, numerical evaluation of (3.14) will show that the sensitivity of $w_{k}$ to these parameters is dominated by their appearance in $\Gamma$, that is, $w_{k}$ increases as $H$ and $k$ increase and as $N$ decreases.

The Bessel functions in (3.14) exhibit damped oscillations [e.g., see Fig. 9.1 of Abramowitz and Stegun (1964, hereafter AS)] whose properties are evident in (A.2), written here to leading order as

$$
J_{n}(\phi) \approx \sqrt{\frac{2}{\pi \phi}} \cos \left(\phi-\frac{n \pi}{2}-\frac{\pi}{4}\right) .
$$

The zero-phase lines of the $J_{n}(\phi)$ functions with arguments $\phi \equiv 2 \sqrt{\alpha t}, 2 \sqrt{\beta t}$, and $2 \sqrt{k N z t}$ are the zeroes of the cosine in (3.16). In view of (2.35), we see that these phase lines are at heights $\tilde{z}=$ const $+(k N t)^{-1}$, which descend with speeds $\tilde{c}=-k^{-1} N^{-1} t^{-2}$. Descending phase fronts are consistent with our discussion of (2.23), which also applies to these $b_{0}$-forced flows. For the $\phi$ considered here, (3.16) also shows that larger changes in $\phi$ are associated with higher-frequency oscillations, that is, oscillation periods decrease with larger $N$, larger $k$ (smaller scale), and larger $z$. These inferences, however, only pertain to the first set of terms in (3.14). To more fully explore the characteristics of the motion, we evaluated (3.14) numerically using the procedure in appendix A.

Time-height plots of $w_{k}$ for the default parameters given in Table 1 and for a larger and smaller value of $N\left(0.015\right.$ and $0.008 \mathrm{~s}^{-1}$, respectively) are shown in Fig. 4. Not surprisingly, stratification provides a lid effect, with a larger $N$ yielding a smaller $w_{k}$. For both wavelengths considered, a $\sim 50 \%$ reduction in $N$ (bottom versus top panels) increases the peak $w_{k}$ by $\sim 50 \%$. For fixed $N$, the peak $w_{k}$ is larger for the smaller scale $(\lambda=600 \mathrm{~km})$ forcing. For the typical free-troposphere value of $N=0.01 \mathrm{~s}^{-1}$ (middle panels), a decrease in $\lambda$ from 1000 to $600 \mathrm{~km}$ nearly doubles $w_{k}$ from about 5 to $10 \mathrm{~cm} \mathrm{~s}^{-1}$. Consistent with our previous discussion, the $w_{k}$ pattern descends with time, and the duration of lowlevel ascent is longer for smaller $N$ and larger $\lambda$. These results suggest competing effects of scale on vertical parcel displacements: a smaller $\lambda$ increases net displacements by increasing $w_{k}$, but decreases net displacements by shortening the ascent phase. As we will 
TABLE 1. Default parameters for the CBL-buoyancy-forced experiments. The analytical solution [(3.14)] was evaluated numerically using the procedure outlined in appendix A with a vertical grid spacing of $50 \mathrm{~m}$ and a time interval of $300 \mathrm{~s}$.

\begin{tabular}{lc}
\hline \hline \multicolumn{1}{c}{ Parameter } & Value \\
\hline$f\left(\right.$ lat $\left.=36.4^{\circ} \mathrm{N}\right)$ & $8.6 \times 10^{-5} \mathrm{~s}^{-1}$ \\
$H$ & $2 \mathrm{~km}$ \\
$\mu$ & $-4 \mathrm{~K}$ \\
$\lambda(=2 \pi / k)$ & 600 and $1000 \mathrm{~km}$ \\
$N$ & $0.01 \mathrm{~s}^{-1}$ \\
\hline
\end{tabular}

see, the former effect is more important than the latter, at least for the parameter values considered.

The case corresponding to the middle-left panel in Fig. 4 is examined in more detail. The initial buoyancy and potential temperature fields are shown in Fig. 5. The
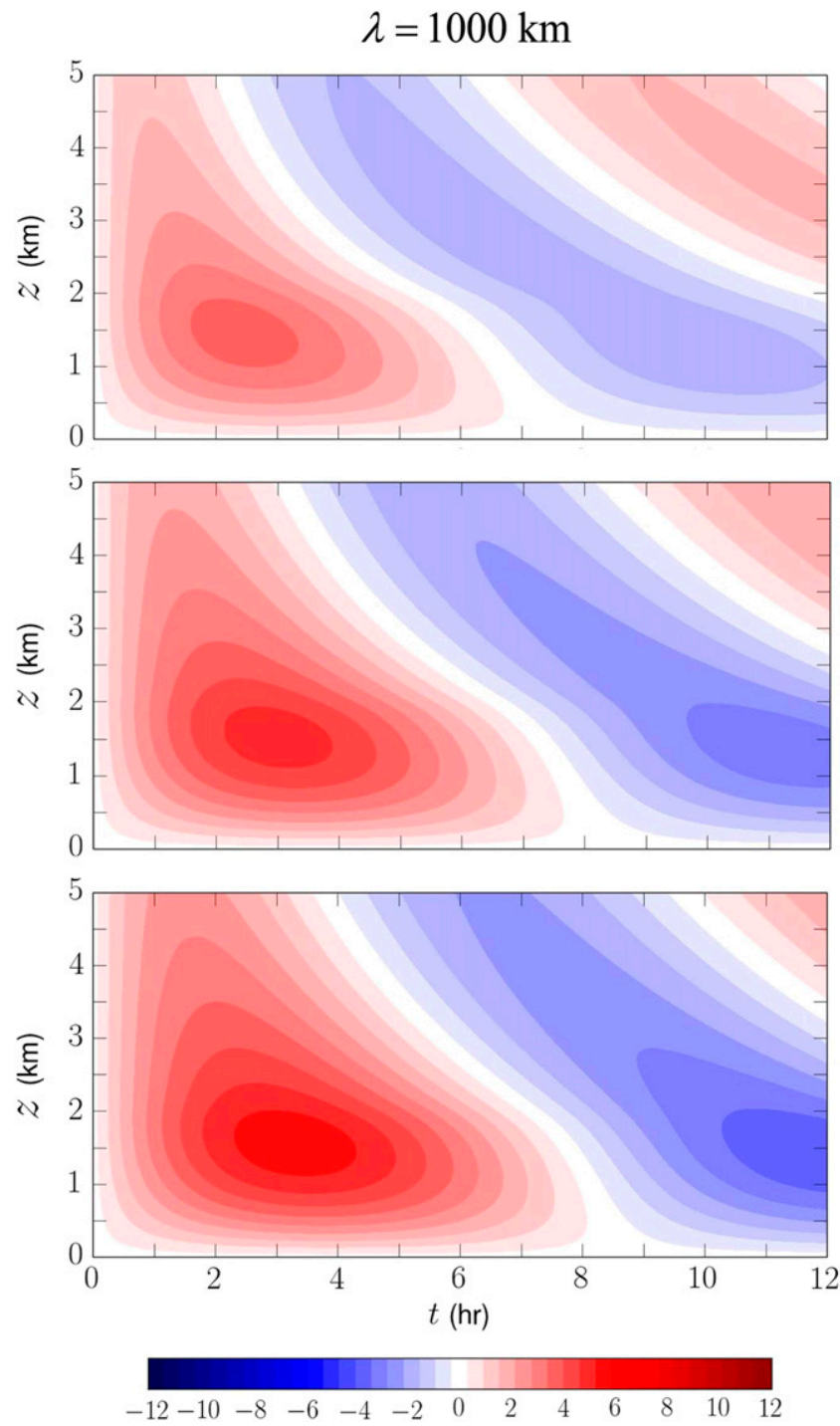

$w(x, z, t)$ field is shown in Fig. 6 . For the first $\sim 1.5 \mathrm{~h}$, the peak $w$ is found slightly below the top of the preexisting CBL. The peak thereafter descends, though not as quickly as the $w=0$ phase line. Figure 4 shows that the largest vertical velocity observed at any time $w_{\max }$ occurs at $\sim 3 \mathrm{~h}$, with low-level ascent lasting $\sim 7 \mathrm{~h}$. By integrating $w$ in a Lagrangian sense, we found that $\Delta z$, the largest net vertical parcel displacement of any air parcel originating within the CBL (parcels initially separated vertically by $100 \mathrm{~m}$ ), was $\sim 750 \mathrm{~m}$. This displacement was attained near the end of the ascent phase for a parcel originating near the half-depth of the CBL.

Experiments were conducted in which one parameter at a time was varied from its default value. Figure 7 shows a strong increase in $w_{\max }$ and $\Delta z$ with decreasing $N$. It should be borne in mind, however, that $N$ in the
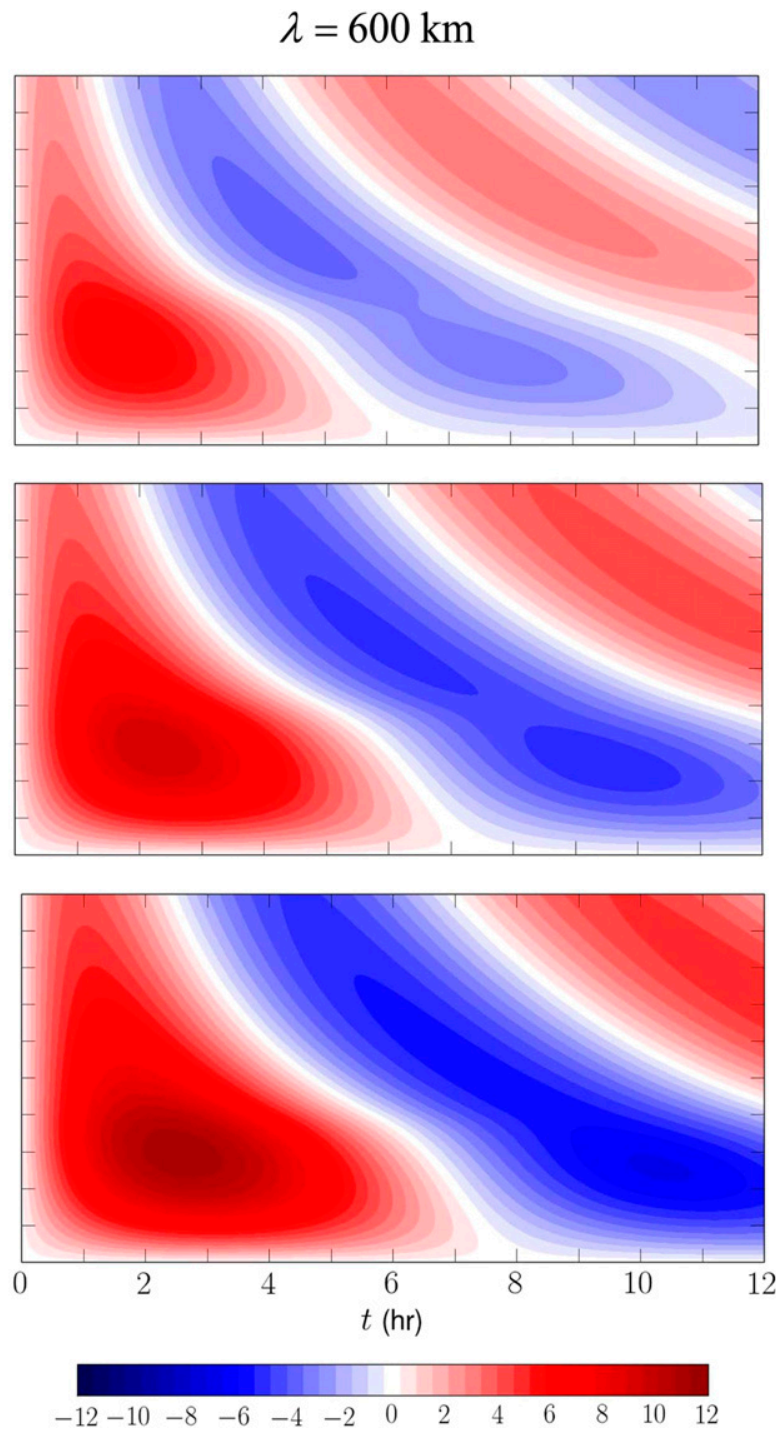

FIG. 4. Time-height diagrams of $w_{k}\left(\mathrm{~cm} \mathrm{~s}^{-1}\right)$ from (3.14) for CBL-buoyancy-forced cases with wavelengths (left) $\lambda=1000 \mathrm{~km}$ and (right) $\lambda=600 \mathrm{~km}$, and buoyancy frequencies (top) $N=0.015 \mathrm{~s}^{-1}$, (middle) $N=0.01 \mathrm{~s}^{-1}$, and (bottom) $N=0.008 \mathrm{~s}^{-1}$. Other parameter values are given in Table 1. 

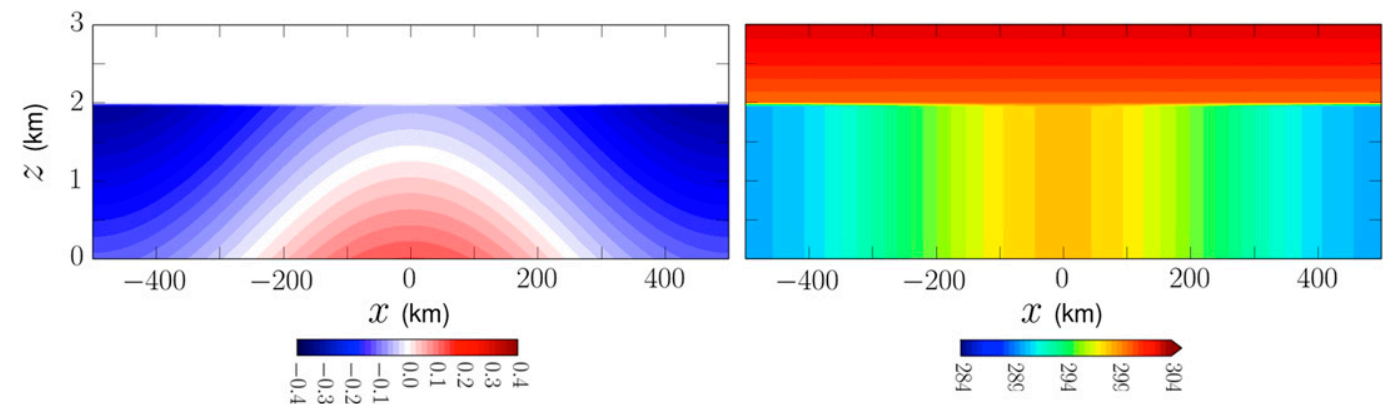

FIG. 5. Vertical cross sections of (left) initial buoyancy $b_{0}\left(\mathrm{~m} \mathrm{~s}^{-2}\right)$ and (right) initial potential temperature $\theta_{0}(\mathrm{~K})$ for the CBL-buoyancy-forced case corresponding to the middle-left panel of Fig. 4.

free troposphere is typically very close to $0.01 \mathrm{~s}^{-1}$ decreasing latitude (i.e., decreasing $f$ ). Figure 9 shows a (Tsuda et al. 1991; Revathy et al. 1996; Yuan et al. 2010). strong increase in $w_{\max }$ and $\Delta z$ with increasing CBL Figure 8 shows an increase in $w_{\max }$ and $\Delta z$ with depth. This result may be of special interest since warm
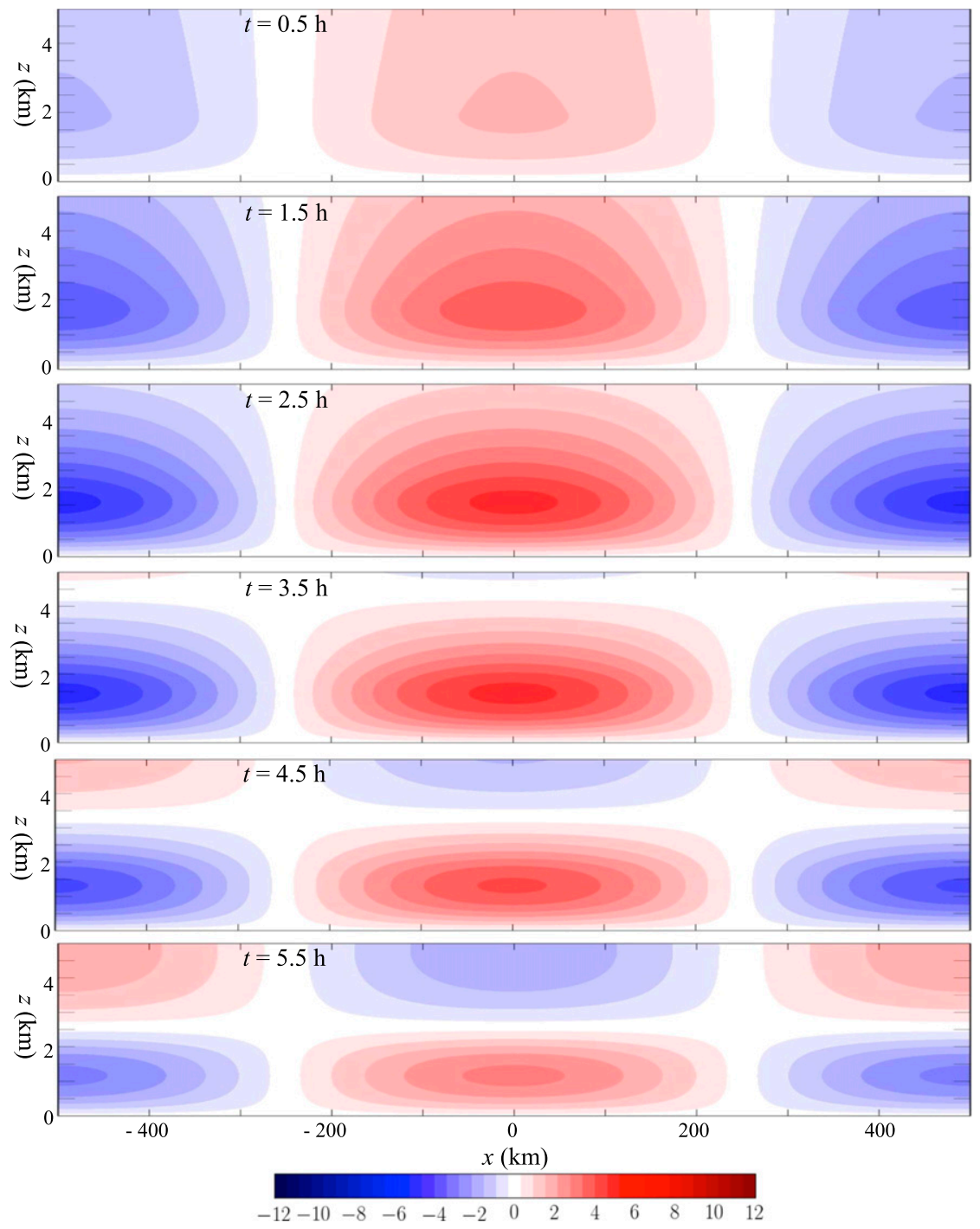

FIG. 6. Evolution of $w\left(\mathrm{~cm} \mathrm{~s}^{-1}\right)$ for the CBL-buoyancy-forced case corresponding to the middle-left panel of Fig. 4. The initial buoyancy field is shown in Fig. 5. (top)-(bottom) Time increases at 1 -h intervals from $t=0.5$ to $5.5 \mathrm{~h}$. 

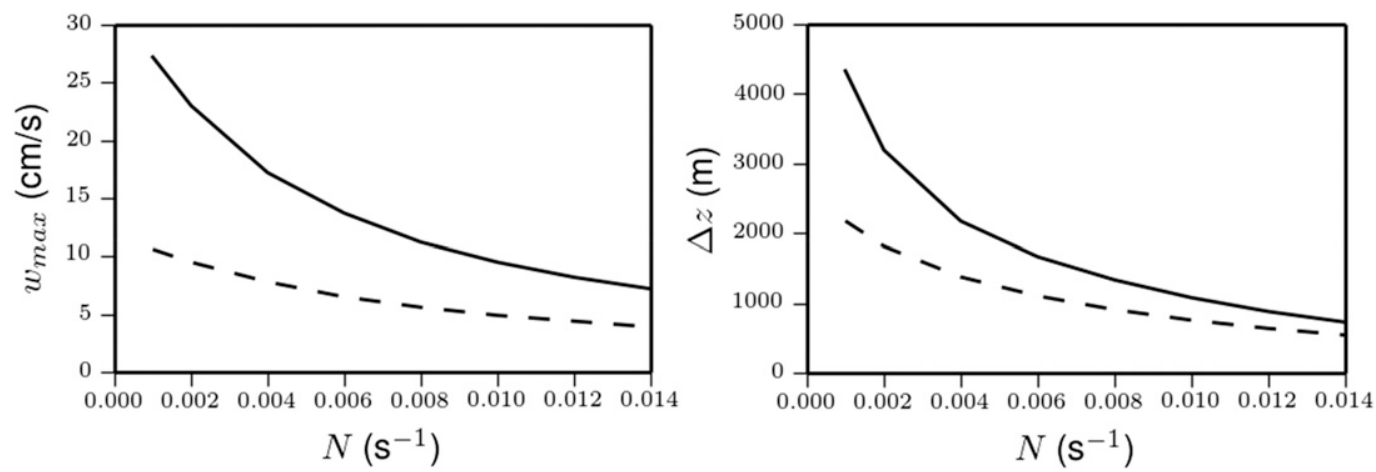

FIG. 7. Domainwide maximum (left) vertical velocity $w_{\max }$ and (right) vertical parcel displacement $\Delta z$ as functions of $N$ for $\lambda=600 \mathrm{~km}$ (solid line) and $\lambda=1000 \mathrm{~km}$ (dashed line). Other parameter values are given in Table 1.

season CBL depths over the southern Great Plains may exceed $2 \mathrm{~km}$ (Schmid and Niyogi 2012; Sawyer and Li 2013; Molod et al. 2015). Figures 7-9 show that $w_{\max }$ and $\Delta z$ are larger for the smaller-scale forcing $(\lambda=600 \mathrm{~km})$.

Last, we consider the $v$ wind component. Recall that the laterally variable part of $v$ is $v_{k}(z, t) \sin k x$, where $x=0$ corresponds to the center of ascent and the center of the warm tongue. In view of (2.4), (2.15b), (2.15c), and (2.11), $v_{k}$ can be written as

$$
v_{k}=\frac{f}{k} \int_{0}^{t} \frac{\partial w_{k}}{\partial z}\left(z, t^{\prime}\right) d t^{\prime}
$$

This result also follows from the time-integrated vertical vorticity equation with forcing due to the stretching of Earth vorticity. Since the peak (positive) $w_{k}$ occurs at a height between 1 and $2 \mathrm{~km}$ above the ground during much of the low-level ascent phase (Figs. 4, 6), and $\partial w_{k} / \partial z$ is positive beneath that height, (3.17) indicates that the low-level $v_{k}$ is positive and increases in magnitude throughout the ascent phase. Thus, $v_{k}(z, t) \sin k x$ is positive (southerly) east of the center of ascent and negative (northerly) west of the center of ascent. These results are consistent with one's intuition concerning the stretching of Earth vorticity (effect on lateral shear of $v$ ), or the deflection of the $u$-wind component by the Coriolis force (effect on $v$; see Fig. 3). Thus, for the typical case where the homogeneous jet is southerly, the peak ascent would be on the western flank of the full inhomogeneous jet. However, one can also envision a jet composed of a homogeneous jet and winds arising from both inhomogeneous $v_{0}$ and $b_{0}$ forcings, with a possible phase shift between the forcings. In such a case, the $v_{0}$ forcing could affect the location of the jet maximum, but have little bearing on the location of the peak ascent (per results from section 2). If the phase shifts between the forcings were arbitrary, there should be no preference for the peak ascent to occur on either flank of the jet, but if the forcings were related, a preference could emerge.

\section{Mesoscale ascent in LLJs during PECAN}

Data from the PECAN project (Geerts et al. 2017) were used as a qualitative check on our hypothesis that the same mechanism that generates nocturnal jets can produce gentle but persistent nocturnal ascent in the presence of a mesoscale warm tongue. The PECAN campaign took place from 1 June to 15 July 2015, over central and western Kansas (KS) and the surrounding states, with an operations center in Hays, KS. Among

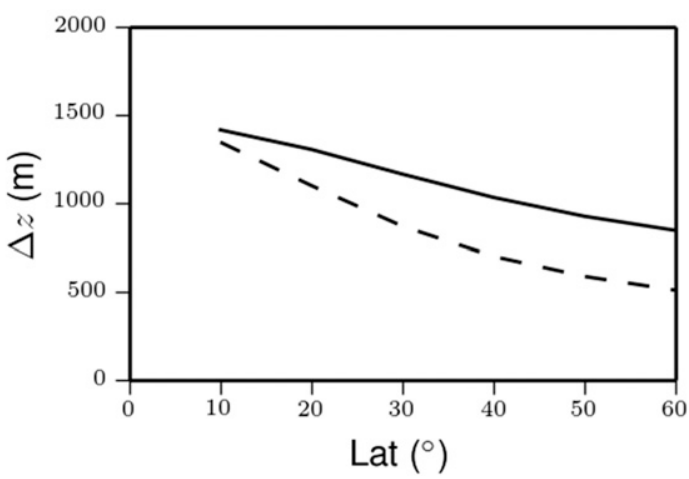

FIG. 8. As in Fig. 7, but as a function of latitude. 

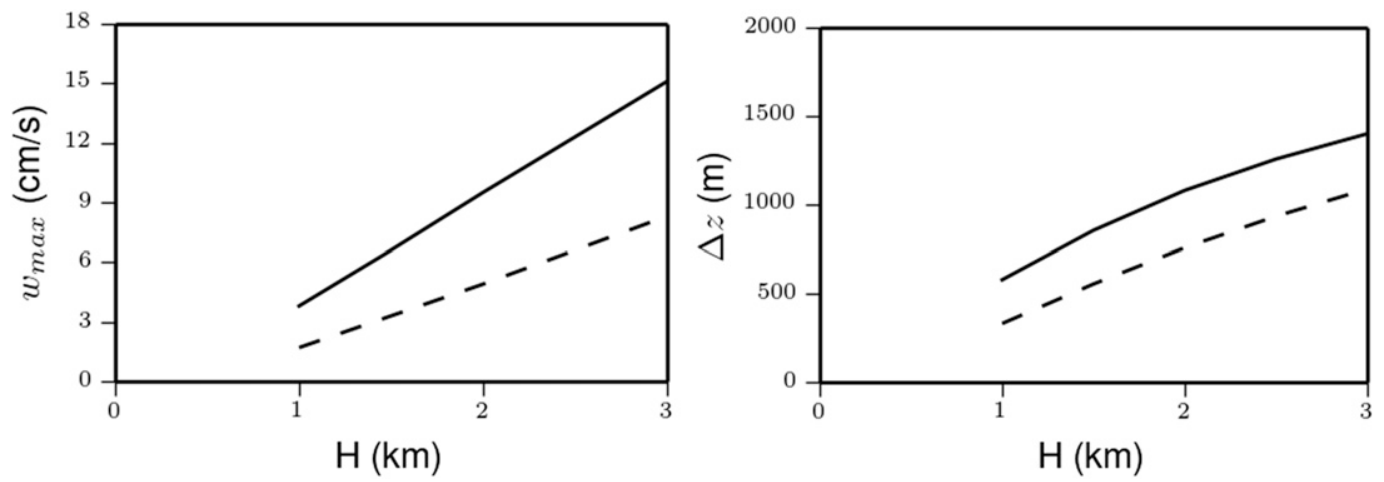

FIG. 9. As in Fig. 7, but as a function of $H$.

the observational platforms were research aircraft, the NCAR Earth Observing Laboratory (EOL) S-Pol Ka radar (S-Pol), mobile Doppler radars, Doppler lidars, Raman lidars, ceilometers, micropulse lidars (MPLs), water vapor differential absorption lidars (WV-DIALs), sodars, wind profilers, and radiosondes. Data were gathered in 31 Intensive Observing Periods (IOPs) and 12 Unofficial Field Operations (UFOs), ${ }^{5}$ each with a focus on MCSs, bores, CI, or LLJs. Only seven IOPs were LLJ or combined CI-LLJ missions, but LLJs were common throughout the campaign.

Several factors complicate comparisons of our theory with PECAN observations. Our model assumes a sudden and complete shutdown of turbulent mixing at sunset instead of a decrease of mixing to small but nonzero levels over the course of an evening transition that begins well before sunset (e.g., Acevedo and Fitzjarrald 2001; Wingo and Knupp 2015). The model does not take into account the Rocky Mountains $\sim 250$ $300 \mathrm{~km}$ west of KS. The model does not make provision for terrain slope and thus cannot account for oscillations arising from the diurnal heating cycle of the sloping Great Plains (so-called Holton mechanism; Holton 1967; see also Fedorovich et al. 2017). Working with a simple analytical model, Du and Rotunno (2014) found that the amplitude and phase of their modeled Great Plains LLJs were in better agreement with data from the North American Regional Reanalysis when both the Holton and Blackadar (1957) mechanisms were accounted for. Shapiro et al. (2016) found that the relative strengths and timings of the LLJ wind maxima in their solutions accounting for Blackadar and Holton mechanisms were in qualitative agreement with the results in $\mathrm{Du}$ and Rotunno (2014). However, the former study also

\footnotetext{
${ }^{5}$ UFOs were rapidly implemented short-duration deployments that targeted unexpected events near Hays on nights when no IOP had been scheduled.
}

showed that while the Holton mechanism could act synergistically with the Blackadar mechanism to produce stronger jets, it was generally not as important as the Blackadar mechanism. An additional slope-related complication is that during the late afternoon, buoyancy increases westward on horizontal or isobaric surfaces that pass through the mixed layer into the surface layer as they obliquely approach the slope. The buoyancy increases with proximity to the heated ground, regardless of whether a warm tongue is present. Fortunately, as shown in appendix $\mathrm{B}$, the $\partial^{2} b_{0} / \partial x^{2}$ forcing term in our theory can, in mixed layers over gentle slopes, be approximated in terms of variations of surface temperature. Use of a warm tongue in terms of temperature along the slope instead of mixed-layer buoyancy along a horizontal or isobaric surface allows us to bypass the above-noted difficulty. However, real surface temperatures inevitably have north-south variations and vary along the slope with more complexity than is represented by one harmonic. Rather than contrive a procedure to fit idealized 2D single-harmonic warm tongues to complex three-dimensional data, we identified warm tongues subjectively (i.e., visually).

A further difficulty is that the anticipated ascent rates $\left(w<\sim 0.1 \mathrm{~m} \mathrm{~s}^{-1}\right.$ ) are beyond the accuracy ranges of the lidars and profilers deployed in PECAN and cannot be verified using $w$ from those instruments. Instead, we estimated $w$ indirectly (and admittedly crudely) by tracking the motion of layered structures in time-height plots $^{6}$ of data from the CL31 ceilometer (belonging to the University of Maryland, Baltimore County) at the S-Pol site ( $\sim 40 \mathrm{~km}$ southwest of Hays), and data from

\footnotetext{
${ }^{6}$ The $449-\mathrm{MHz}$ profiler, MPL, and WV-DIAL figures shown here were adapted from plots at the PECAN field catalog (NCAR EOL field catalog, https://doi.org/10.5065/D6SQ8XFB). The CL31 ceilometer figure was generated from archived data (Vermeesch 2016).
} 

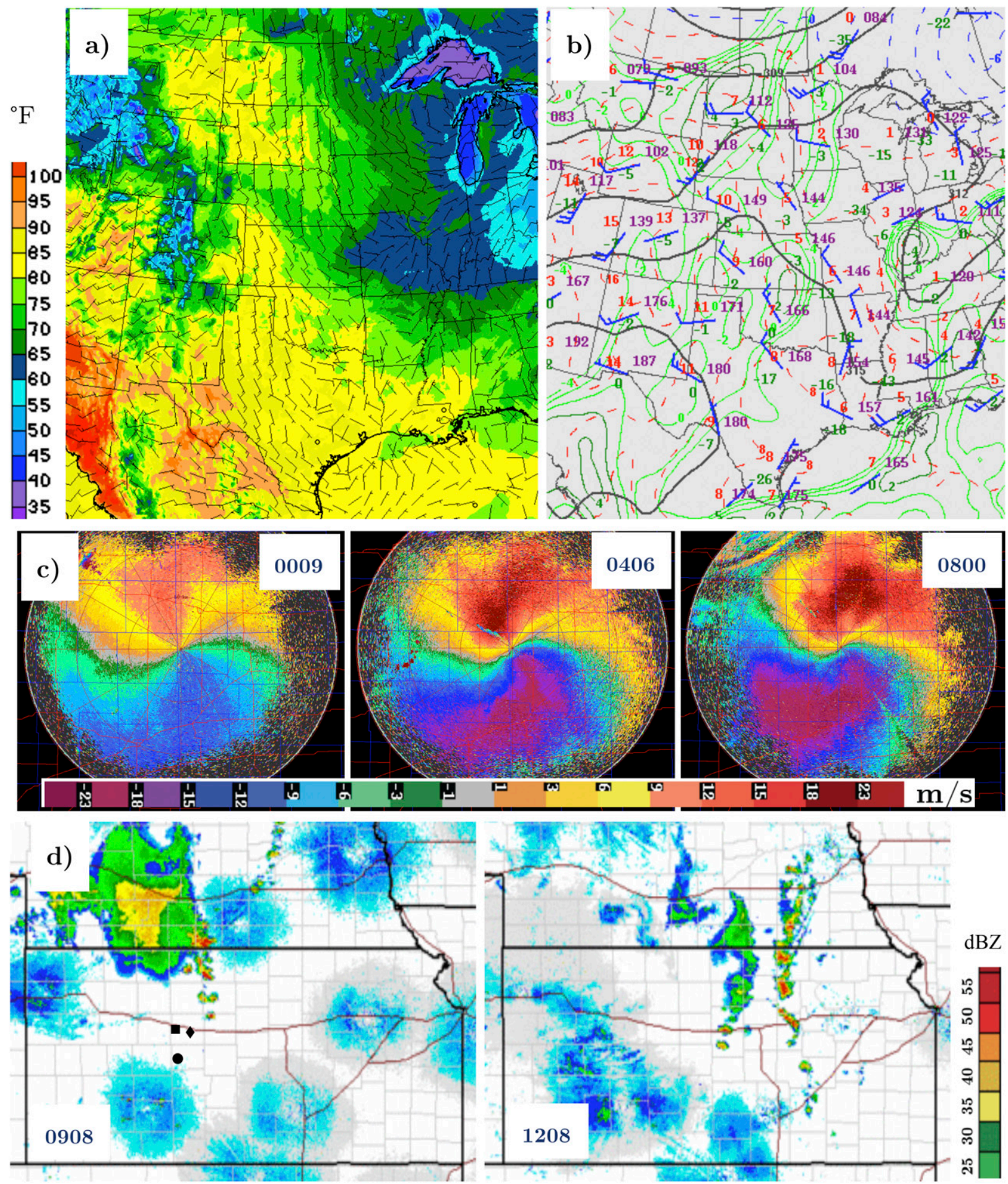

FIG. 10. Atmospheric conditions on 2 Jun 2015: (a) 0000 UTC HRRR 2-m temperature analysis; (b) 0000 UTC NOAA/NWS/Storm Prediction Center (SPC) 700-hPa height, temperature, and wind analysis; (c) S-Pol radial winds on the $0.5^{\circ}$ scan surface at (left) 0009, (center) 0406, and (right) 0800 UTC; and (d) radar reflectivity over KS and southern NE from the NWS National Mosaic at (left) 0908 and (right) 1208 UTC. Range rings (thin circles) in (c) are plotted at 50-km intervals. The left panel of (d) shows locations of S-Pol (dot), Ellis (square), and Hays (diamond). 

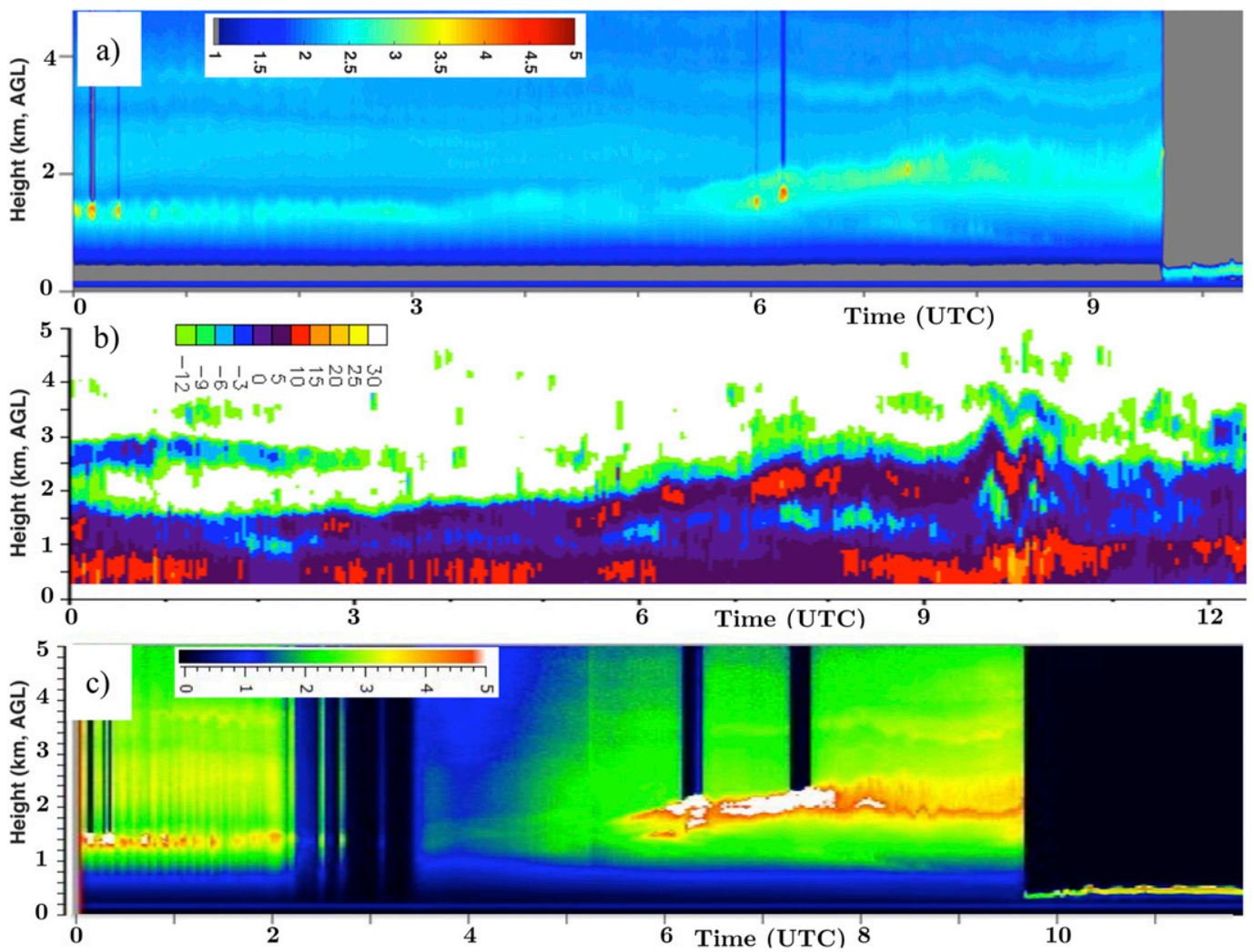

FIG. 11. Evolution of selected profiles on 2 Jun 2015: (a) WV-DIAL relative backscatter, (b) 449-MHz profiler signal-to-noise ratio (dB), and (c) MPL relative backscatter $\left(\mathrm{C} \mathrm{km}^{2} \mu \mathrm{s}^{-1}\right)$ at Ellis.

the NCAR EOL 449-MHz profiler, Millersville University MPL, and NCAR EOL WV-DIAL at Ellis, KS ( $\sim 25 \mathrm{~km}$ northwest of Hays), whenever such structures were evident (often they were not).

We identified four cases in which Blackadar-like LLJs, persistent weak rising motion, and pristine $\mathrm{CI}^{7}$ developed at night after an afternoon in which conditions roughly conformed to the restrictions of our theory: 1 June (first day of PECAN, no IOP scheduled), 2 June (IOP1, a dry run), 14 June (UFO2, a CI mission), and 5 July (IOP19, a bore/MCS mission). The 1 June case was fairly similar to the 2 June case, and will not be described here. The CI episodes on 1 June, 2 June, and 5 July are discussed

\footnotetext{
${ }^{7}$ We define pristine CI (or CI in pristine environments) loosely to mean convection that initiates without influence from preexisting convection or forcing from surface boundaries.

${ }^{8}$ Times are given in coordinated universal time (UTC), which is $5 \mathrm{~h}$ ahead of central daylight time (CDT). For reference, (i) sunset at Hays on 1 June ( 2100 CDT) corresponds to $\sim 0200$ UTC 2 June, (ii) data collections at 1900 CDT 1 June correspond to 0000 UTC 2 June, and (iii) midnight (0000 CDT) corresponds to 0500 UTC of the same day.
}

in Gebauer (2017). The 5 July case is also discussed in Reif and Bluestein (2017) and in Trier et al. (2017).

Overviews of conditions on 2 June 2015 are presented in Fig. 10 (see Figs. 12 and 14 for conditions on 14 June and 5 July 2015, respectively). ${ }^{8}$ Surface and $700-\mathrm{hPa}$ analyses at 0000 UTC showed quiescent synoptic conditions over KS, with any fronts located well north of the region. The 0000 UTC 2-m surface temperature analyses [from the NCEP High Resolution Rapid Refresh model (HRRR)] showed temperatures increasing westward across much of KS, with roughly north-south-oriented warm tongues centered over the western or west-central part of the state.

The 0000 UTC low-level base reflectivity fields from the NWS National Mosaic (not shown) indicated that KS was free of convective activity and mesoscale surface boundaries, while CBLs were evident in $\sim 0000$ UTC PECAN soundings ${ }^{9}$ from Brewster, Ellis, and Greensburg (all in KS), and/or 0000 UTC NWS soundings from Dodge City, KS, and North Platte,

\footnotetext{
${ }^{9}$ Not all PECAN soundings were available at $\sim 0000$ UTC, and none were available for UFO2.
} 

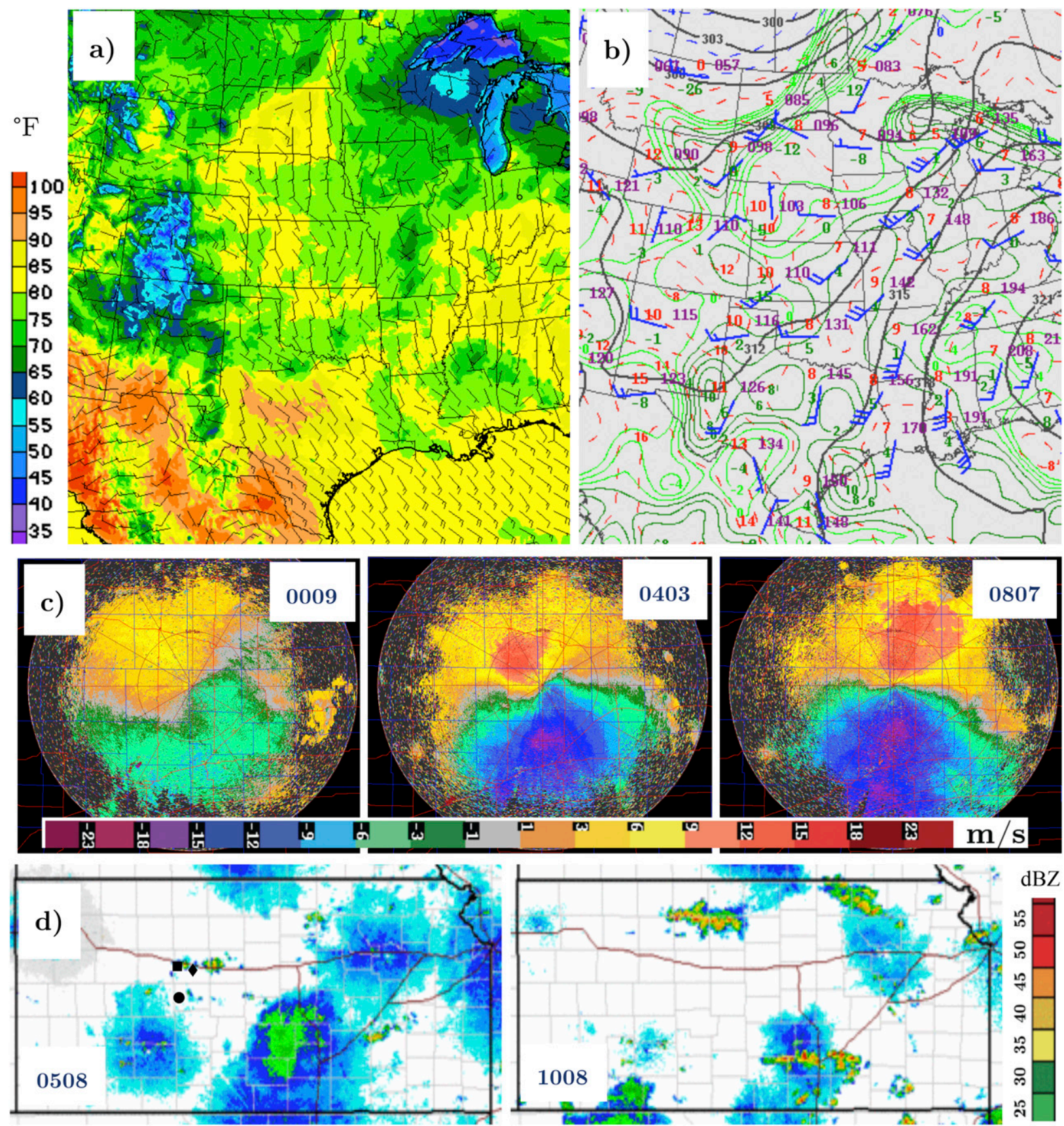

FIG. 12. Atmospheric conditions on 14 Jun 2015: (a) 0000 UTC HRRR 2-m temperature analysis; (b) 0000 UTC NOAA/NWS/SPC 700-hPa height, temperature, and wind analysis; (c) S-Pol radial winds on the $0.5^{\circ}$ scan surface at (left) 0009, (center) 0403 , and (right) 0807 UTC; and (d) radar reflectivity over KS from the NWS National Mosaic at (left) 0508 and (right) 1008 UTC. Range rings (thin circles) in (c) are plotted at 50-km intervals. The left panel of (d) shows locations of S-Pol (dot), Ellis (square), and Hays (diamond).

Nebraska (NE), and/or 449-MHz profiler data from Ellis. Although the $700-\mathrm{hPa}$ winds over central and western KS were weak on these afternoons (with a small northerly component evident on 2 June), the low-level thermal winds inferred from the 2-m temperature analyses were northerly, and the estimated low-level geostrophic winds had large southerly components. Against this backdrop of warm, dry afternoon conditions with southerly low-level geostrophic winds, it was not surprising to see the nocturnal development of southerly LLJs in Doppler velocity imagery from regional WSR-88Ds and the S-Pol radar. Figure 10c shows the evolution of the S-Pol 

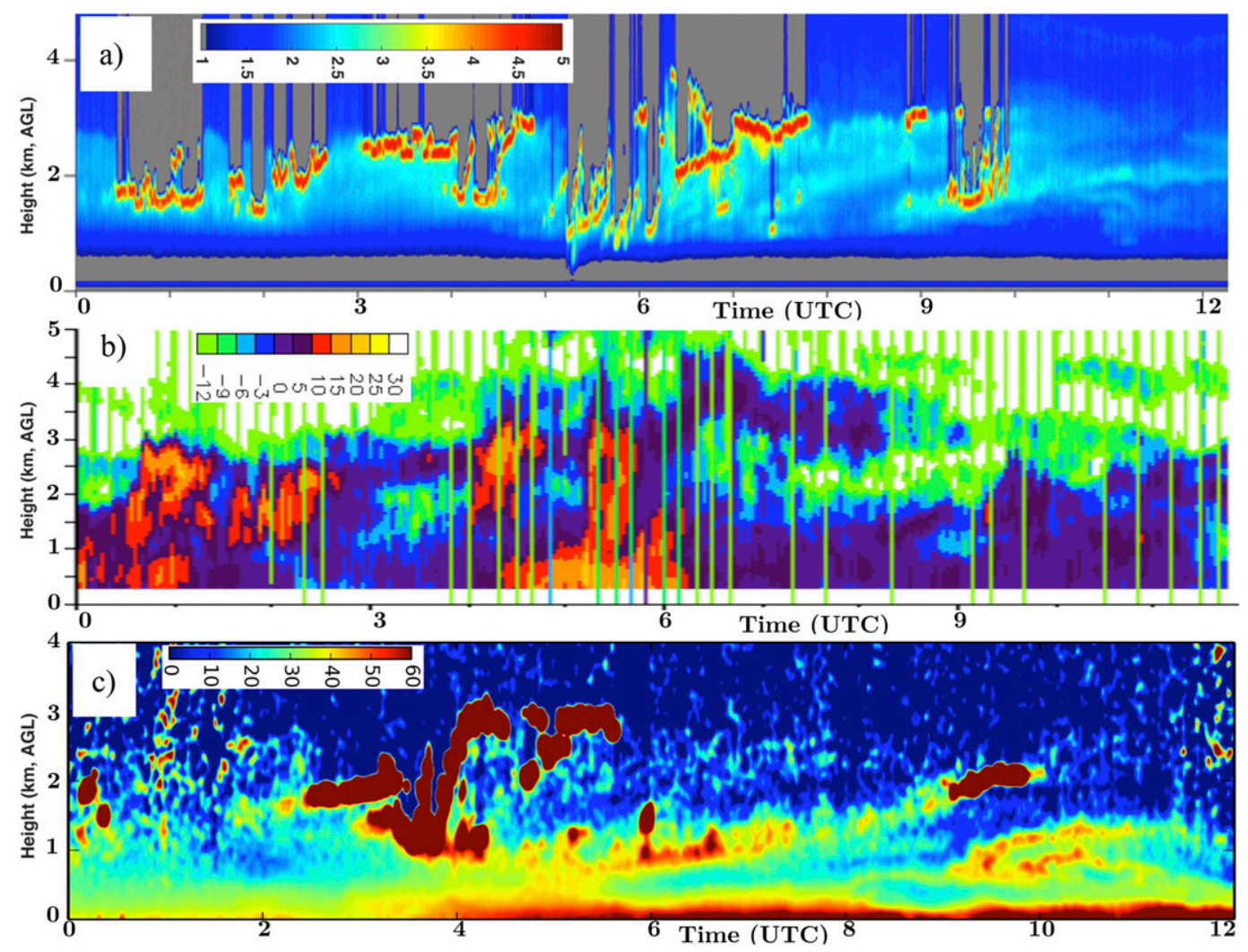

FIG. 13. Evolution of selected profiles on 14 Jun 2015: (a) WV-DIAL relative backscatter and (b) 449-MHz profiler signal-to-noise ratio $(\mathrm{dB})$ at Ellis and (c) CL31 ceilometer backscatter $\left[\left(10^{5} \mathrm{srad} \mathrm{km}\right)^{-1}\right]$ at the S-Pol location.

radial winds for the 2 June case (see Figs. $12 \mathrm{c}$ and $14 \mathrm{c}$ for the 14 June and 15 July cases).$^{10}$ On each night, the wind speeds at $\sim 0800$ UTC at the level of the jet maximum (evident $\sim 50 \mathrm{~km}$ from the S-Pol on the $0.5^{\circ}$ tilt, which is $\sim 400 \mathrm{~m}$ above the ground) were about twice their values at $\sim 0000$ UTC. Over the same period the wind vectors rotated clockwise from southeasterly to southwesterly.

From Global Telecommunications System (GTS) surface station plots at $\sim 0000$ UTC 2 June, 14 June, and 5 July, we estimate temperature changes of $\sim 22^{\circ}, \sim 11^{\circ}$, and $\sim 17^{\circ} \mathrm{F}$, respectively, across the warm tongues (so $\mu=-6.1,-3.1$, and $-4.7 \mathrm{~K}$, respectively). From these plots we also estimate (crudely) warm-tongue wavelengths of $\sim 1100 \mathrm{~km}$ on 2 and 14 June and $\sim 1300 \mathrm{~km}$ on 5 July. From 449-MHz profiler data (along with MPL data on 14 June and 5 July and a 0000 UTC PECAN sounding on 5 July), we estimate 0000 UTC CBL depths at Ellis of

\footnotetext{
${ }^{10}$ In interpreting these plots, we assumed that the winds vary with height but are relatively constant in the horizontal. This assumption is reasonable for scans of optically clear air when no fronts or mesoscale boundaries are present.
}

$\sim 1.5 \mathrm{~km}$ on 2 June, $\sim 2.2 \mathrm{~km}$ on 14 June, and $\sim 2.0 \mathrm{~km}$ on 5 July. Using these parameters, the $b_{0}$-forced analytical model of section 3 produces peak vertical velocities $w_{\max }$ of $4.3,3.8$, and $4.0 \mathrm{~cm} \mathrm{~s}^{-1}$, respectively. The corresponding peak vertical parcel displacements $\Delta z \sim 725,605$, and $675 \mathrm{~m}$ are attained at times $t \sim 7.7,7.1$, and $7.5 \mathrm{~h}$, for parcels initially at heights $z \sim 650,1150$, and $1050 \mathrm{~m}$.

On 2 June, the first of two rounds of convection initiated around 0900 UTC from a dissipating MCS (Fig. 10d). The northern part of the line and an arc of cells that formed northeast of the MCS may have been affected by the MCS [perhaps triggered by an MCSgenerated outflow or bore as in Carbone et al. (1990)], but some of the cells in the southern part of the line appeared to be unrelated to the preexisting convection. About 1100 UTC, a second line of cells with seemingly more pristine origins emerged east of the first line. Imagery from the WV-DIAL, 449-MHz profiler, and MPL at Ellis provided the best evidence of long-lived ascent starting after sunset (Fig. 11). From an estimated lift of $1 \mathrm{~km}$ between 0300 and 0800 UTC, we obtain $w \sim 6 \mathrm{~cm} \mathrm{~s}^{-1}$ ( $w_{\text {max }}$ produced by the analytical model was $\left.4.3 \mathrm{~cm} \mathrm{~s}^{-1}\right)$. 



FIG. 14. Atmospheric conditions on 5 Jul 2015: (a) 0000 UTC HRRR 2-m temperature analysis; (b) 0000 UTC NOAA/NWS/SPC 700-hPa height, temperature, and wind analysis; (c) S-Pol radial winds on the $0.5^{\circ}$ scan surface at (left) 0005, (center) 0406, and (right) 0807 UTC; and (d) radar reflectivity over KS from the NWS National Mosaic at (left) 0358 and (right) 0758 UTC. Range rings (thin circles) in (c) are plotted at 50-km intervals. The left panel of (d) shows locations of S-Pol (dot), Ellis (square), and Hays (diamond).

The UFO2 mission on 14 June was described in the mission's web page notes (http://catalog.eol.ucar.edu/ pecan/) as a "surprise CI UFO mission." Isolated small convective cells developed around 0500 UTC (Fig. 12d) near Hays and over several locations south and east of Hays. The convection gradually intensified and consolidated into three lines. Imagery from the WV-DIAL and 449-MHz profiler at Ellis and (especially) from the CL31 ceilometer at the S-Pol location (Fig. 13) suggests ascent of $\sim 1.5 \mathrm{~km}$ from 0200 to 0800 UTC over Ellis and ascent of $\sim 1.5 \mathrm{~km}$ from 0400 to 1000 UTC over S-Pol, indicative of $w \sim 7 \mathrm{~cm} \mathrm{~s}^{-1}$ over 

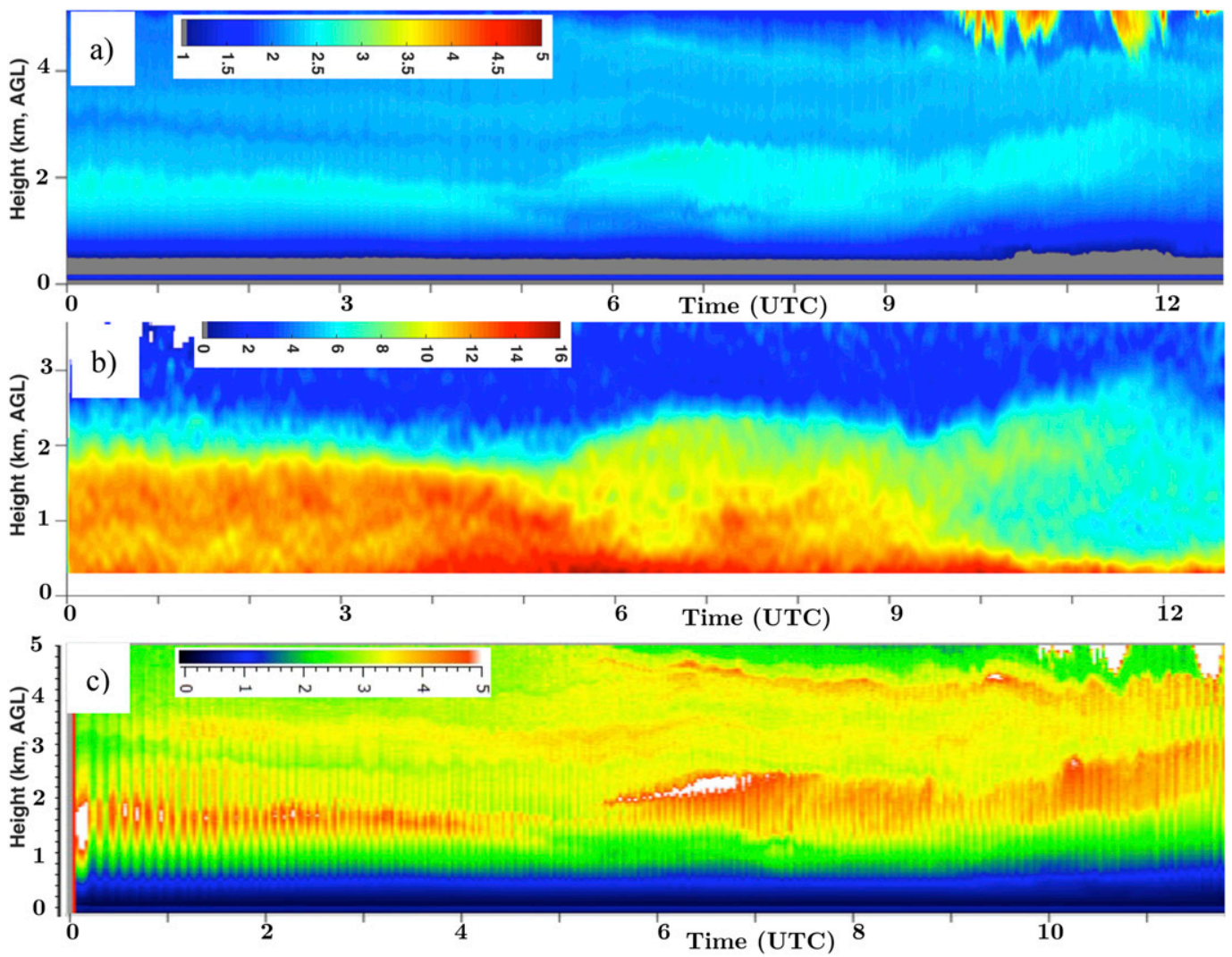

FIG. 15. Evolution of selected profiles on 5 Jul 2015: (a) WV-DIAL relative backscatter, (b) WV-DIAL absolute humidity $\left(\mathrm{g} \mathrm{m}^{-3}\right)$, and (c) MPL relative backscatter $\left(\mathrm{C} \mathrm{km}^{2} \mu \mathrm{s}^{-1}\right)$ at Ellis.

both locations ( $w_{\max }$ produced in the analytical model was $\left.3.8 \mathrm{~cm} \mathrm{~s}^{-1}\right)$.

IOP 19 (5 July) provided a good dataset of pristine CI. The first round of convection developed shortly before 0400 UTC in western KS (Fig. 14d). Around 0700 UTC a second line of convection developed east of the first line. The lines drifted eastward and intensified, reaching peak strength between 0900 and 1000 UTC. Imagery from the WV-DIAL and MPL at Ellis (Fig. 15) suggests lift of $\sim 1.3 \mathrm{~km}$ from 0500 to 1200 UTC, from which we estimate $w \sim 5 \mathrm{~cm} \mathrm{~s}^{-1}\left(w_{\max }\right.$ produced in the analytical model was $4.0 \mathrm{~cm} \mathrm{~s}^{-1}$ ). This inferred ascent started about $2 \mathrm{~h}$ later than on the other two nights and was actually $1 \mathrm{~h}$ after the onset of the first CI.

In a case study of IOP19, Reif and Bluestein (2017) classified the $\mathrm{CI}$ on this night as a no-boundary mode. Their figure of the NCEP Global Forecast System (GFS) analysis of the 700-hPa omega $\omega$ (vertical-pressure velocity) field at 0600 UTC showed ascent over much of central and western KS (Fig. 16) ${ }^{11}$ though with

\footnotetext{
${ }^{11}$ Our Fig. 16 is a corrected version of Fig. 21d of Reif and Bluestein (2017), which had an error in the units for $\omega$ (D. Reif 2017, personal communication).
}

much mesoscale variability. The peak GFS value $\omega \sim-0.4 \mathrm{~Pa} \mathrm{~s}^{-1}\left(w \sim 4 \mathrm{~cm} \mathrm{~s}^{-1}\right)$ over central KS is similar to the $5 \mathrm{~cm} \mathrm{~s}^{-1}$ estimate at Ellis.

Trier et al. (2017) examined CI and mesoscale ascent in IOP19 and four other PECAN cases. IOP19 was the only one of their selected cases in which convection initiated without an obvious connection to a front or other surface boundary. Profiles of $\omega$ representative of mesoscale motions were estimated on triangular domains ${ }^{12}$ using PECAN radiosonde winds. For IOP19, the $\omega$ profiles derived from averages of 0300 and 0600 UTC data indicated relatively slow ascent (peak $\omega \sim-0.2 \mathrm{~Pa} \mathrm{~s}^{-1}$ ), which started relatively high above the ground $(\omega<0$ for heights above the $\sim 725-\mathrm{hPa}$ level). However, when data at just the later time (0600 UTC) were used, the peak $\omega$ doubled to $\sim-0.4 \mathrm{~Pa} \mathrm{~s}^{-1}$, and ascent began closer to the ground $(\omega<0$ for heights above the $\sim 800-\mathrm{hPa}$ level). These results are consistent with the ascent seen in Fig. 15, that is, low-level ascent of $\omega \sim-0.4 \mathrm{~Pa} \mathrm{~s}^{-1}$ at Ellis that did not begin until $\sim 0500$

\footnotetext{
${ }^{12}$ The vertices of these triangles coincided with the locations of PECAN soundings. One vertex used in the IOP19 analysis coincided with Ellis.
} 


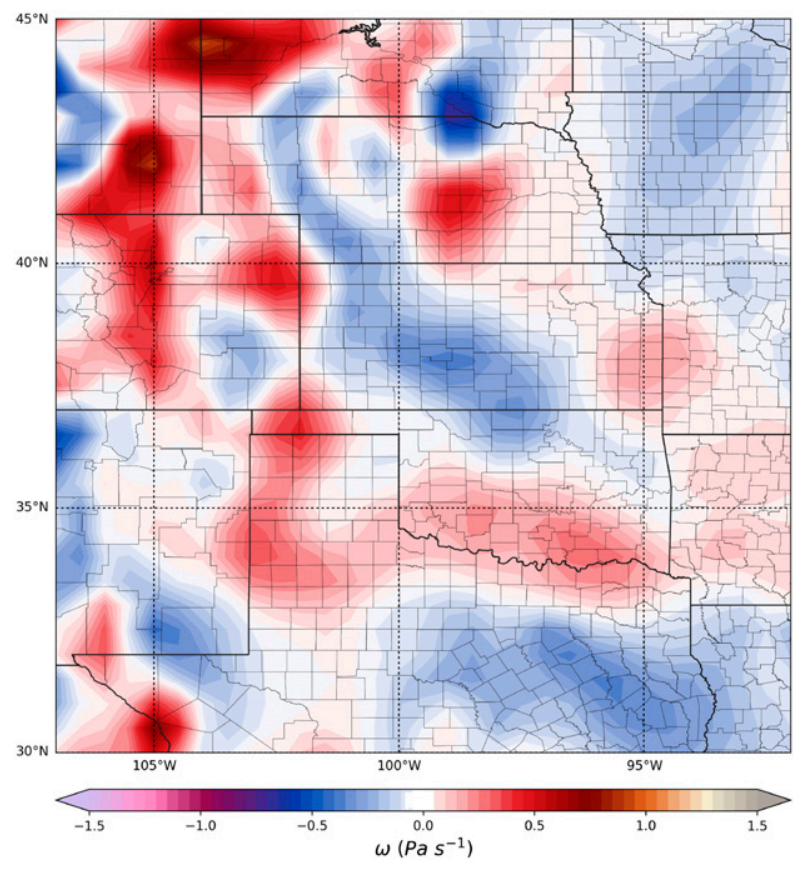

FIG. 16. 700-hPa GFS analysis of $\omega$ at 0600 UTC 5 Jul 2015. Figure courtesy of Dylan Reif.

UTC. Trier et al. (2017) also obtained $\omega$ from 50-member ensemble forecasts initialized at 0000 UTC using data from a mesoscale data assimilation system. The $\omega$ field at 0600 UTC from the ensemble member whose forecast was in closest agreement with observations (Fig. 16a of Trier et al. 2017) was similar to the GFS-analyzed $\omega$ field, at least over KS (Fig. 21d of Reif and Bluestein 2017; our Fig. 16).

\section{Summary and final remarks}

A hypothesis that weak but persistent mesoscale ascent can arise from the shutdown of turbulent mixing in a horizontally inhomogeneous CBL at sunset is illustrated using a simple $2 \mathrm{D}$ model in which the initial state is described by a zero-order jump model of a CBL, and the nocturnal motion is inviscid. The shutdown of turbulence triggers IOs (associated with the horizontal mean part of the CBL) from which Blackadar-like LLJs emerge as well as inertia-gravity waves and persistent ( $\sim 6-8 \mathrm{~h})$ low-level ascent associated with the inhomogeneity. Two types of inhomogeneity are considered: 1) a laterally varying southerly wind in the CBL and free atmosphere and 2) a lateral variation of the CBL buoyancy, as in a warm tongue. The latter is found to be much more effective than the former in generating vertical motion. For parameter values typical of warm season CBLs, the model yields vertical parcel displacements (e.g., $0.3-1 \mathrm{~km})$ that are of magnitudes that may facilitate nocturnal CI. We note that an extensive north-south-oriented warm tongue is a characteristic feature of the warm season climatology of the Great Plains, as can be inferred, for example, from Fig. 2 of Pu and Dickinson (2014).

For the buoyancy-forced motions we find the following:

- The vertical velocity pattern descends with time (more accurately, the zero isoline descends). Low-level ascent is eventually replaced by subsidence.

- The peak ascent increases with increasing amplitude of the buoyancy variation, increasing CBL depth, increasing wavenumber $k$ (decreasing wavelength $\lambda$ ) and decreasing $N$.

- The duration of low-level ascent is longer for smaller $N$ and larger $\lambda$.

- Of the competing tendencies for a smaller $\lambda$ to increase net vertical parcel displacements by increasing the vertical velocity, but decrease net displacements by shortening the ascent phase, the former is more important.

The ascent produced by the model is in qualitatively good agreement with that inferred in three cases from the PECAN field project. However, because of the assumptions underpinning the model, the subtlety of the physical effects we are exploring, and the uncontrolled nature of field experiments, the comparisons have been necessarily crude. A more rigorous exploration of our theory using controlled experiments with mesoscale numerical weather prediction models should be more illuminating.

Acknowledgments. We thank Dylan Reif, Elizabeth Smith, Petra Klein, and David Parsons (at the School of Meteorology, University of Oklahoma) for helpful discussions about nocturnal CI and LLJs over the Great Plains. William Brown, Scot Loehrer, and Brooks Snyder (at UCAR) provided valuable assistance with PECAN data. This research was supported by the National Science Foundation under Grant AGS-135698.

\section{APPENDIX A}

\section{Bessel Functions of the First Kind}

We evaluate Bessel functions of the first kind of integer order $J_{n}(\phi)$ ( $n$ is an integer, $\phi$ is real) using standard results described, for example, in AS. For small arguments $(\phi \leq 8)$, we evaluate $J_{n}(\phi)$ as the sum of the first 20 terms of the ascending series representation in 
(9.1.10) in AS (with the gamma function rewritten as a factorial):

$$
J_{n}(\phi)=\left(\frac{1}{2} \phi\right)^{n} \sum_{k=0}^{\infty} \frac{\left(-\phi^{2} / 4\right)^{k}}{k !(n+k) !} .
$$

For larger arguments $(\phi>8)$, we use Hankel's asymptotic expansion [(9.2.5) in AS] with the first two terms retained in the series [(9.2.9) and (9.2.10) in AS]:

$$
\begin{aligned}
J_{n}(\phi) & \sim \sqrt{\frac{2}{\pi \phi}}[P(n, \phi) \cos \chi-Q(n, \phi) \sin \chi], \\
P(n, \phi) & \sim 1-\frac{\left(4 n^{2}-1\right)\left(4 n^{2}-9\right)}{2 !(8 \phi)^{2}}, \text { and } \\
Q(n, \phi) & \sim \frac{4 n^{2}-1}{8 \phi}-\frac{\left(4 n^{2}-1\right)\left(4 n^{2}-9\right)\left(4 n^{2}-25\right)}{3 !(8 \phi)^{3}},
\end{aligned}
$$

where $\chi \equiv \phi-(n / 2+1 / 4) \pi$.

Graphs of $J_{n}(\phi)$ (e.g., Fig. 9.1 of AS) show that these functions undergo damped oscillations. This behavior can also be seen analytically in (A.2).

It will be convenient to use the recurrence relation in (9.1.27) in AS:

$$
2 \phi^{-1} J_{1}(\phi)=J_{0}(\phi)+J_{2}(\phi) .
$$

\section{APPENDIX B}

\section{Approximating the Forcing Term $\partial^{2} b_{0} / \partial x^{2}$ over a Shallow Slope}

For warm tongues in mixed layers similar to those idealized in section 3-but over gentle slopes-the $b_{0}$-forcing term in (2.27) can be approximated in terms of along-slope temperature variations. We demonstrate this for slope angles $\alpha \sim 0.1^{\circ}$ representative of KS $(\sim 1-\mathrm{km}$ elevation gain over the $\sim 650-\mathrm{km}$ length of the state), along-slope gradients in $\theta_{0}$ of $\sim 1 \mathrm{~K}(100 \mathrm{~km})^{-1}$, and $<2 \mathrm{~K}$ vertical changes in $\theta_{0}$ within mixed layers $\sim 1-2 \mathrm{~km}$ deep. We work in a slope-following Cartesian coordinate system ( $x_{s}$ is the downslope coordinate, $z_{s}$ is the slope-normal coordinate), for which $\partial x_{s} / \partial x=\cos \alpha \approx 1, \partial z_{s} / \partial x=\sin \alpha$, and $\partial z / \partial x_{s}=-\sin \alpha$.

Taking $\partial^{2} / \partial x^{2}$ of (2.7) yields

$$
\frac{\partial^{2} b_{0}}{\partial x^{2}} \approx \frac{g}{\theta_{r}}\left(\frac{\partial^{2} \theta_{0}}{\partial x_{s}^{2}}+2 \sin \alpha \frac{\partial^{2} \theta_{0}}{\partial x_{s} \partial z_{s}}+\sin ^{2} \alpha \frac{\partial^{2} \theta_{0}}{\partial z_{s}^{2}}\right) .
$$

In the mixed layer, $\partial^{2} \theta_{0} / \partial x_{s}^{2}$ is much larger than $\sin \alpha \partial^{2} \theta_{0} / \partial x_{s} \partial z_{s}$ and $\sin ^{2} \alpha \partial^{2} \theta_{0} / \partial z_{s}^{2}$, so

$$
\frac{\partial^{2} b_{0}}{\partial x^{2}} \approx \frac{g}{\theta_{r}} \frac{\partial^{2} \theta_{0}}{\partial x_{s}^{2}} \quad\left(\text { for } b_{0} \text { in the mixed layer }\right)
$$

Assuming $\theta_{0}$ varies with $x_{s}$ in a similar manner for all $z_{s}$ in the mixed and surface layers, we can write its distribution in the mixed layer as: $\theta_{0}\left(x_{s}, z_{s}\right)=F\left(x_{s}\right) G\left(z_{s}\right)=$ $F\left(x_{s}\right) G(0) G\left(z_{s}\right) / G(0)=\theta_{\text {sfc }} G\left(z_{s}\right) / G(0)$, where $\theta_{\text {sfc }} \equiv$ $\theta_{0}\left(x_{s}, 0\right)$, and $F$ and $G$ are unspecified functions. For mixed-layer $\theta_{0}$ within $\sim 10 \mathrm{~K}$ of $\theta_{\text {sfc }}$, we can approximate $G\left(z_{s}\right) / G(0) \approx 1$, and write (B.2) as

$$
\frac{\partial^{2} b_{0}}{\partial x^{2}}=\frac{g}{\theta_{r}} \frac{\partial^{2} \theta_{\text {sfc }}}{\partial x_{s}^{2}} \quad\left(\text { for } b_{0} \text { in mixed layer }\right) .
$$

Differentiating $\theta \equiv T(1000 \mathrm{hPa} / p)^{\kappa}$ logarithmically with respect to $x_{s}$, and replacing $\theta, T, p$ in the denominators by standard atmosphere profiles $\tilde{\theta}, \tilde{T}, \tilde{p}$ yields, approximately,

$$
\frac{1}{\tilde{\theta}} \frac{\partial \theta}{\partial x_{s}}=\frac{1}{\tilde{T}} \frac{\partial T}{\partial x_{s}}-\frac{\kappa}{\tilde{p}} \frac{\partial p}{\partial x_{s}} .
$$

Writing $p$ as the sum of $\tilde{p}$ and $p^{\prime}$ (deviation from $\tilde{p}$ ), the last term in (B.4) becomes

$$
\frac{\kappa}{\tilde{p}} \frac{\partial p}{\partial x_{s}}=\frac{\kappa}{\tilde{p}} \frac{\partial p^{\prime}}{\partial x_{s}}+\frac{\kappa}{\tilde{p}} \frac{\partial \tilde{p}}{\partial x_{s}} .
$$

Assuming $d \tilde{p} / d z=-\tilde{\rho} g(\tilde{\rho}$ is standard atmosphere density), the last term in (B.5) becomes

$\frac{\kappa}{\tilde{p}} \frac{\partial \tilde{p}}{\partial x_{s}}=-\frac{\kappa}{\tilde{p}} \frac{\partial \tilde{p}}{\partial z} \sin \alpha=\frac{\kappa \tilde{\rho} g \sin \alpha}{\tilde{p}}=\frac{\kappa g \sin \alpha}{R \tilde{T}}=\frac{\sigma}{\tilde{T}}$,

where $\sigma \equiv \kappa g \sin \alpha / R=g \sin \alpha / c_{p}$. We can then write (B.4) as

$$
\frac{1}{\tilde{\theta}} \frac{\partial \theta}{\partial x_{s}}=\frac{1}{\tilde{T}} \frac{\partial T}{\partial x_{s}}-\frac{\kappa}{\tilde{p}} \frac{\partial p^{\prime}}{\partial x_{s}}-\frac{\sigma}{\tilde{T}} .
$$

For $p^{\prime}$ varying as much as $10 \mathrm{hPa}$ across KS, the secondto-last term in (B.7) is much smaller than the last term, and we can approximate (B.7) as

$$
\frac{\partial \theta}{\partial x_{s}}=\left(\frac{1000 \mathrm{hPa}}{\tilde{p}}\right)^{\kappa}\left(\frac{\partial T}{\partial x_{s}}-\sigma\right)
$$

Differentiating (B.8) with respect to $x_{s}$ and using (B.6) for $(\kappa / \tilde{p}) \partial \tilde{p} / \partial x_{s}$ yields

$$
\frac{\partial^{2} \theta}{\partial x_{s}^{2}}=\left(\frac{1000 \mathrm{hPa}}{\tilde{p}}\right)^{\kappa}\left(\frac{\partial^{2} T}{\partial x_{s}^{2}}-\frac{\sigma}{\tilde{T}} \frac{\partial T}{\partial x_{s}}+\frac{\sigma^{2}}{\tilde{T}}\right) .
$$


On the slope, $\partial^{2} T / \partial x_{s}^{2}$ is much larger than $(\sigma / \tilde{T}) \partial T / \partial x_{s}$ or $\sigma^{2} / \tilde{T}$, while $(1000 \mathrm{hPa} / \tilde{p})^{\kappa} \approx 1$. Thus, $\partial^{2} \theta_{\text {sfc }} / \partial x_{s}^{2} \approx$ $\partial^{2} T_{\text {scc }} / \partial x_{s}^{2}$, and we can approximate (B.3) as

$$
\frac{\partial^{2} b_{0}}{\partial x^{2}}=\frac{g}{\theta_{r}} \frac{\partial^{2} T_{\text {sfc }}}{\partial x_{s}^{2}} \quad\left(\text { for } b_{0} \text { in mixed layer }\right)
$$

\section{REFERENCES}

Abramowitz, M., and I. A. Stegun, Eds., 1964: Handbook of Mathematical Functions with Formulas, Graphs, and Mathematical Tables. National Bureau of Standards, 1046 pp.

Acevedo, O. C., and D. R. Fitzjarrald, 2001: The early evening surface-layer transition: Temporal and spatial variability. J. Atmos. Sci., 58, 2650-2667, https://doi.org/10.1175/15200469(2001)058<2650:TEESLT $>2.0$. CO 2 .

Arritt, R. W., T. D. Rink, M. Segal, D. P. Todey, C. A. Clark, M. J. Mitchell, and K. M. Labas, 1997: The Great Plains low-level jet during the warm season of 1993. Mon. Wea. Rev., 125, 2176-2192, https://doi.org/10.1175/1520-0493(1997)125<2176: TGPLLJ > 2.0.CO;2.

Arya, S. P. S., 1977: Suggested revisions to certain boundary layer parameterization schemes used in atmospheric circulation models. Mon. Wea. Rev., 105, 215-227, https://doi.org/10.1175/ 1520-0493(1977)105<0215:SRTCBL>2.0.CO;2.

Astling, E. G., J. Paegle, E. Miller, and C. J. O’Brien, 1985: Boundary layer control of nocturnal convection associated with a synoptic scale system. Mon. Wea. Rev., 113, 540-552, https://doi.org/ 10.1175/1520-0493(1985)113<0540:BLCONC $>2.0 . C O ; 2$.

Augustine, J. A., and F. Caracena, 1994: Lower tropospheric precursors to nocturnal MCS development over the central United States. Wea. Forecasting, 9, 116-135, https://doi.org/ 10.1175/1520-0434(1994)009<0116:LTPTNM >2.0.CO;2.

Baas, P., F. C. Bosveld, H. Klein Baltink, and A. A. M. Holtslag, 2009: A climatology of nocturnal low-level jets at Cabauw. J. Appl. Meteor. Climatol., 48, 1627-1642, https://doi.org/ 10.1175/2009JAMC1965.1.

Blackadar, A. K., 1957: Boundary-layer wind maxima and their significance for the growth of nocturnal inversions. Bull. Amer. Meteor. Soc., 38, 283-290.

, 1959: Final report on study of forecasting low-level wind gradients. AFCRC Contract AF19(604)-2059, Pennsylvania State University, $96 \mathrm{pp}$.

Bleeker, W., and M. J. Andre, 1951: On the diurnal variation of precipitation, particularly over central U. S. A., and its relation to large-scale orographic circulation systems. Quart. J. Roy. Meteor. Soc., 77, 260-271, https://doi.org/10.1002/qj.49707733211.

Bonner, W. D., 1966: Case study of thunderstorm activity in relation to the low-level jet. Mon. Wea. Rev., 94, 167-178, https:// doi.org/10.1175/1520-0493(1966)094<0167:CSOTAI >2.3.CO;2. , 1968: Climatology of the low-level jet. Mon. Wea. Rev., 96, 833-850, https://doi.org/10.1175/1520-0493(1968)096<0833: COTLLJ $>2.0 . \mathrm{CO} ; 2$.

- S. Esbensen, and R. Greenberg, 1968: Kinematics of the lowlevel jet. J. Appl. Meteor., 7, 339-347, https://doi.org/10.1175/ 1520-0450(1968)007<0339:KOTLLJ>2.0.CO;2.

Buajitti, K., and A. K. Blackadar, 1957: Theoretical studies of diurnal wind-structure variations in the planetary boundary layer. Quart. J. Roy. Meteor. Soc., 83, 486-500, https://doi.org/ 10.1002/qj.49708335804.
Carbone, R. E., and J. D. Tuttle, 2008: Rainfall occurrence in the U.S. warm season: The diurnal cycle. J. Climate, 21, 4132 4146, https://doi.org/10.1175/2008JCLI2275.1.

_ J. W. Conway, N. A. Crook, and M. W. Moncrieff, 1990: The generation and propagation of a nocturnal squall line. Part I: Observations and implications for mesoscale predictability. Mon. Wea. Rev., 118, 26-49, https://doi.org/10.1175/15200493(1990)118<0026:TGAPOA $>2.0$. CO;2.

— J. D. Tuttle, D. A. Ahijevych, and S. B. Trier, 2002: Inferences of predictability associated with warm season precipitation episodes. J. Atmos. Sci., 59, 2033-2056, https://doi.org/10.1175/15200469(2002)059<2033:IOPAWW >2.0.CO;2.

Charba, J., 1974: Application of gravity current model to analysis of squall-line gust front. Mon. Wea. Rev., 102, 140-156, https://doi.org/10.1175/1520-0493(1974)102<0140: AOGCMT $>2.0 . \mathrm{CO} ; 2$.

Chen, R., and L. Tomassini, 2015: The role of moisture in summertime low-level jet formation and associated rainfall over the East Asian monsoon region. J. Atmos. Sci., 72, 3871-3890, https://doi.org/10.1175/JAS-D-15-0064.1.

Clark, A. J., W. A. Gallus, and T. Chen, 2007: Comparison of the diurnal precipitation cycle in convection-resolving and nonconvection-resolving mesoscale models. Mon. Wea. Rev., 135 , 3456-3473, https://doi.org/10.1175/MWR3467.1.

Coleman, T. A., and K. R. Knupp, 2011: Radiometer and profiler analysis of the effects of a bore and solitary wave on the stability of the nocturnal boundary layer. Mon. Wea. Rev., 139, 211-223, https://doi.org/10.1175/2010MWR3376.1.

Crysler, K. A., R. A. Maddox, L. R. Hoxit, and B. M. Muller, 1982: Diurnal distribution of very heavy precipitation over the central and eastern United States. Natl. Wea. Dig., 7 (1), 33-37.

Dai, A., F. Giorgi, and K. E. Trenberth, 1999: Observed and modelsimulated diurnal cycles of precipitation over the contiguous United States. J. Geophys. Res., 104, 6377-6402, https:// doi.org/10.1029/98JD02720.

Davis, C. A., K. W. Manning, R. E. Carbone, S. B. Trier, and J. D. Tuttle, 2003: Coherence of warm-season continental rainfall in numerical weather prediction models. Mon. Wea. Rev., 131, 2667-2679, https://doi.org/10.1175/1520-0493(2003)131<2667: COWCRI $>2.0$.CO;2.

Doetsch, G., 1961: Guide to the Applications of Laplace Transforms. Van Nostrand, $255 \mathrm{pp}$.

Drobinski, P., and T. Dubos, 2009: Linear breeze scaling: From large-scale land/sea breezes to mesoscale inland breezes. Quart. J. Roy. Meteor. Soc., 135, 1766-1775, https://doi.org/ 10.1002/qj.496.

Du, Y., and R. Rotunno, 2014: A simple analytical model of the nocturnal low-level jet over the Great Plains of the United States. J. Atmos. Sci., 71, 3674-3683, https://doi.org/10.1175/ JAS-D-14-0060.1.

Easterling, D. R., and P. J. Robinson, 1985: The diurnal variation of thunderstorm activity in the United States. J. Climate Appl. Meteor., 24, 1048-1058, https://doi.org/10.1175/1520-0450 (1985)024<1048:TDVOTA>2.0.CO;2.

Erdélyi, A., W. Magnus, F. Oberhettinger, and F. G. Tricomi, 1954: Tables of Integral Transforms. Vol. 1, McGraw-Hill, 391 pp.

Fedorovich, E., 1995: Modeling the atmospheric convective boundary layer within a zero-order jump approach: An extended theoretical framework. J. Appl. Meteor., 34, 1916-1928, https://doi.org/ 10.1175/1520-0450(1995)034<1916:MTACBL > 2.0.CO;2.

_ J. A. Gibbs, and A. Shapiro, 2017: Numerical study of nocturnal low-level jets over gently sloping terrain. J. Atmos. Sci., 74, 2813-2833, https://doi.org/10.1175/JAS-D-17-0013.1. 
Fovell, R. G., G. L. Mullendore, and S.-H. Kim, 2006: Discrete propagation in numerically simulated nocturnal squall lines. Mon. Wea. Rev., 134, 3735-3752, https://doi.org/10.1175/ MWR3268.1.

French, A. J., and M. D. Parker, 2010: The response of simulated nocturnal convective systems to a developing low-level jet. J. Atmos. Sci., 67, 3384-3408, https://doi.org/10.1175/ 2010JAS3329.1.

Fritsch, J. M., R. J. Kane, and C. R. Chelius, 1986: The contribution of mesoscale convective weather systems to the warm-season precipitation in the United States. J. Climate Appl. Meteor., 25 , 1333-1345, https://doi.org/10.1175/1520-0450(1986)025<1333: TCOMCW $>2.0 . \mathrm{CO} ; 2$.

Gebauer, J. G., 2017: Convection initiation by heterogeneous Great Plains low-level jets. M.S. thesis, School of Meteorology, University of Oklahoma, 162 pp., https://hdl.handle.net/ $11244 / 50439$.

Geerts, B., R. Damiani, and S. Haimov, 2006: Finescale vertical structure of a cold front as revealed by an airborne Doppler radar. Mon. Wea. Rev., 134, 251-271, https://doi.org/10.1175/ MWR3056.1.

_ and Coauthors, 2017: The 2015 Plains Elevated Convection at Night field project. Bull. Amer. Meteor. Soc., 98, 767-786, https://doi.org/10.1175/BAMS-D-15-00257.1.

Gill, A. E., 1982: Atmosphere-Ocean Dynamics. Academic Press, $662 \mathrm{pp}$.

Haghi, K. R., D. B. Parsons, and A. Shapiro, 2017: Bores observed during IHOP_2002: The relationship of bores to the nocturnal environment. Mon. Wea. Rev., 145, 3929-3946, https://doi.org/ 10.1175/MWR-D-16-0415.1.

Hane, C., C. Ziegler, and H. B. Bluestein, 1993: Investigation of the dryline and convective storms initiated along the dryline: Field experiments during COPS-91. Bull. Amer. Meteor. Soc., 74, 2133-2145, https://doi.org/10.1175/1520-0477(1993)074<2133: IOTDAC $>2.0 . \mathrm{CO} ; 2$.

Higgins, R. W., Y. Yao, E. S. Yarosh, J. E. Janowiak, and K. C. Mo, 1997: Influence of the Great Plains low-level jet on summertime precipitation and moisture transport over the central United States. J. Climate, 10, 481-507, https://doi.org/10.1175/ 1520-0442(1997)010<0481:IOTGPL > 2.0.CO;2.

Hoecker, W. H., 1963: Three southerly low-level jet systems delineated by the Weather Bureau special pibal network of 1961. Mon. Wea. Rev., 91, 573-582, https://doi.org/10.1175/15200493(1963)091<0573:TSLJSD>2.3.CO;2.

Holton, J. R., 1967: The diurnal boundary layer wind oscillation above sloping terrain. Tellus, 19, 199-205, https://doi.org/ 10.1111/j.2153-3490.1967.tb01473.x.

Jirak, I. L., and W. R. Cotton, 2007: Observational analysis of the predictability of mesoscale convective systems. Wea. Forecasting, 22, 813-838, https://doi.org/10.1175/WAF1012.1.

Karyampudi, V. M., S. E. Koch, C. Chen, J. W. Rottman, and M. L. Kaplan, 1995: The influence of the Rocky Mountains on the 13-14 April 1986 severe weather outbreak. Part II: Evolution of a prefrontal bore and its role in triggering a squall line. Mon. Wea. Rev., 123, 1423-1446, https://doi.org/10.1175/15200493(1995)123<1423:TIOTRM > 2.0.CO;2.

Kincer, J. B., 1916: Daytime and nighttime precipitation and their economic significance. Mon. Wea. Rev., 44, 628-633, https://doi org/10.1175/1520-0493(1916)44<628:DANPAT >2.0.CO;2.

Koch, S. E., and W. L. Clark, 1999: A nonclassical cold front observed during COPS-91: Frontal structure and the process of severe storm initiation. J. Atmos. Sci., 56, 2862-2890, https://doi.org/ 10.1175/1520-0469(1999)056<2862:ANCFOD>2.0.CO;2.
— R. E. Golus, and P. B. Dorian, 1988: A mesoscale gravity wave event observed during CCOPE. Part II: Interactions between mesoscale convective systems and the antecedent waves. Mon. Wea. Rev., 116, 2545-2569, https://doi.org/ 10.1175/1520-0493(1988)116<2545:AMGWEO>2.0.CO;2.

Lee, M.-I., S. D. Schubert, M. J. Suarez, J.-K. E. Schemm, H.-L. Pan, and S.-H. Yoo, 2008: Role of convection triggers in the simulation of the diurnal cycle of precipitation over the United States Great Plains in a general circulation model. J. Geophys. Res., 113, D02111, https://doi.org/10.1029/2007JD008984.

Liebmann, B., G. N. Kiladis, C. S. Vera, A. C. Saulo, and L. M. V. Carvalho, 2004: Subseasonal variations of rainfall in South America in the vicinity of the low-level jet east of the Andes and comparison to those in the South Atlantic Convergence Zone. J. Climate, 17, 3829-3842, https://doi.org/10.1175/15200442(2004)017<3829:SVORIS >2.0.CO;2.

Lin, Y.-L., 2007: Mesoscale Dynamics. Cambridge University Press, $630 \mathrm{pp}$.

Lynn, B. H., W.-K. Tao, and P. J. Wetzel, 1998: A study of landscape-generated deep moist convection. Mon. Wea. Rev., 126, 928-942, https://doi.org/10.1175/1520-0493(1998)126<0928: ASOLGD > 2.0.CO;2.

Maddox, R. A., 1983: Large-scale meteorological conditions associated with midlatitude mesoscale convective complexes. Mon. Wea. Rev., 111, 1475-1493, https://doi.org/10.1175/15200493(1983)111<1475:LSMCAW>2.0.CO;2.

—, and G. K. Grice, 1983: Synoptic characteristics of heavy rainfall events in South Texas. Natl. Wea. Dig., 8 (3), 8-16.

— C. F. Chappell, and L. R. Hoxit, 1979: Synoptic and meso- $\alpha$ scale aspects of flash flood events. Bull. Amer. Meteor. Soc., 60 , 115-123, https://doi.org/10.1175/1520-0477-60.2.115.

, K. W. Howard, D. L. Bartels, and D. M. Rodgers, 1986: Mesoscale convective complexes in the middle latitudes. $M e$ soscale Meteorology and Forecasting, P. S. Ray, Ed., Amer. Meteor. Soc., 390-413.

Mahfouf, J.-F., E. Richard, and P. Mascart, 1987: The influence of soil and vegetation on the development of mesoscale circulations. J. Climate Appl. Meteor., 26, 1483-1495, https://doi.org/ 10.1175/1520-0450(1987)026<1483:TIOSAV>2.0.CO;2.

Mahoney, W. P., 1988: Gust front characteristics and the kinematics associated with interacting thunderstorm outflows. Mon. Wea. Rev., 116, 1474-1491, https://doi.org/10.1175/15200493(1988) $116<1474:$ GFCATK $>2.0 . C O ; 2$.

Mahrt, L., J. Sun, D. Vickers, J. I. MacPherson, J. R. Pederson, and R. L. Desjardins, 1994: Observations of fluxes and inland breezes over a heterogeneous surface. J. Atmos. Sci., 51, 2484-2499, https://doi.org/10.1175/1520-0469(1994)051<2484: OOFAIB $>2.0 . \mathrm{CO} ; 2$

Marsham, J. H., and D. J. Parker, 2006: Secondary initiation of multiple bands of cumulonimbus over southern Britain. II: Dynamics of secondary initiation. Quart. J. Roy. Meteor. Soc., 132, 1053-1072, https://doi.org/10.1256/qj.05.152.

—, S. B. Trier, T. M. Weckwerth, and J. W. Wilson, 2011: Observations of elevated convection initiation leading to a surfacebased squall line during 13 June IHOP_2002. Mon. Wea. Rev., 139, 247-271, https://doi.org/10.1175/2010MWR3422.1.

McPherson, R. A., 2007: A review of vegetation-atmosphere interactions and their influences on mesoscale phenomena. Prog. Phys. Geogr., 31, 261-285, https://doi.org/10.1177/ 0309133307079055

Means, L. L., 1952: On thunderstorm forecasting in the central United States. Mon. Wea. Rev., 80, 165-189, https://doi.org/ 10.1175/1520-0493(1952)080<0165:OTFITC $>2.0 . C O ; 2$. 
Mitchell, M. J., R. W. Arritt, and K. Labas, 1995: A climatology of the warm season Great Plains low-level jet using wind profiler observations. Wea. Forecasting, 10, 576-591, https://doi.org/ 10.1175/1520-0434(1995)010<0576:ACOTWS >2.0.CO;2.

Molod, A., H. Salmun, and M. Dempsey, 2015: Estimating planetary boundary layer heights from NOAA Profiler network wind profiler data. J. Atmos. Oceanic Technol., 32, 1545-1561, https://doi.org/10.1175/JTECH-D-14-00155.1.

Monaghan, A. J., D. L. Rife, J. O. Pinto, C. A. Davis, and J. R. Hannan, 2010: Global precipitation extremes associated with diurnally varying low-level jets. J. Climate, 23, 5065-5084, https://doi.org/10.1175/2010JCLI3515.1.

Orville, R. E., and R. W. Henderson, 1986: Global distribution of midnight lightning - September 1977 to August 1978. Mon. Wea. Rev., 114, 2640-2653, https://doi.org/10.1175/15200493(1986) $114<2640$ :GDOMLS $>2.0$.CO;2.

Paegle, J., 1978: A linearized analysis of diurnal boundary layer convergence over the topography of the United States. Mon. Wea. Rev., 106, 492-502, https://doi.org/10.1175/15200493(1978)106<0492:ALAODB > 2.0.CO;2.

, and D. W. McLawhorn, 1973: Correlation of nocturnal thunderstorms and boundary-layer convergence. Mon. Wea. Rev., 101, 877-883, https://doi.org/10.1175/1520-0493(1973) 101<0877:CONTAB > 2.3.CO;2.

—_ and G. E. Rasch, 1973: Three-dimensional characteristics of diurnally varying boundary-layer flows. Mon. Wea. Rev., 101, 746-756, https://doi.org/10.1175/1520-0493(1973)101<0746: TCODVB $>2.3 . \mathrm{CO} ; 2$.

Pitchford, K. L., and J. London, 1962: The low-level jet as related to nocturnal thunderstorms over Midwest United States. J. Appl. Meteor., 1, 43-47, https://doi.org/10.1175/1520-0450(1962)001<0043: TLLJAR $>2.0 . \mathrm{CO} ; 2$.

Pu, B., and R. E. Dickinson, 2014: Diurnal spatial variability of Great Plains summer precipitation related to the dynamics of the low-level jet. J. Atmos. Sci., 71, 1807-1817, https://doi.org/ 10.1175/JAS-D-13-0243.1.

Reif, D. W., and H. B. Bluestein, 2017: A 20-year climatology of nocturnal convection initiation over the central and southern Great Plains during the warm season. Mon. Wea. Rev., 145, 1615-1639, https://doi.org/10.1175/MWR-D-16-0340.1.

Revathy, K., S. R. Prabhakaran Nair, and B. V. Krishna Murthy, 1996: Deduction of temperature profile from MST radar observations of vertical wind. Geophys. Res. Lett., 23, 285-288, https://doi.org/10.1029/96GL00086.

Riley, G. T., M. G. Landin, and L. F. Bosart, 1987: The diurnal variability of precipitation across the central Rockies and adjacent Great Plains. Mon. Wea. Rev., 115, 11611172, https://doi.org/10.1175/1520-0493(1987)115<1161: TDVOPA $>2.0 . \mathrm{CO} ; 2$.

Salio, P., M. Nicolini, and E. J. Zipser, 2007: Mesoscale convective systems over southeastern South America and their relationship with the South American low-level jet. Mon. Wea. Rev., 135, 1290-1309, https://doi.org/10.1175/MWR3305.1.

Sawyer, V., and Z. Li, 2013: Detection, variations and intercomparison of the planetary boundary layer depth from radiosonde, lidar and infrared spectrometer. Atmos. Environ., 79, 518-528, https://doi.org/10.1016/j.atmosenv.2013.07.019.

Schmid, P., and D. Niyogi, 2012: A method for estimating planetary boundary layer heights and its application over the ARM Southern Great Plains site. J. Atmos. Oceanic Technol., 29, 316-322, https://doi.org/10.1175/JTECH-D-11-00118.1.

Segal, M., and R. W. Arritt, 1992: Nonclassical mesoscale circulations caused by surface sensible heat-flux gradients. Bull.
Amer. Meteor. Soc., 73, 1593-1604, https://doi.org/10.1175/ 1520-0477(1992)073<1593:NMCCBS>2.0.CO;2.

Shapiro, A., and E. Fedorovich, 2010: Analytical description of a nocturnal low-level jet. Quart. J. Roy. Meteor. Soc., 136, 1255-1262, https://doi.org/10.1002/qj.628.

-,- , and S. Rahimi, 2016: A unified theory for the Great Plains nocturnal low-level jet. J. Atmos. Sci., 73, 3037-3057, https://doi.org/10.1175/JAS-D-15-0307.1.

Song, H., W. Lin, Y. Lin, A. B. Wolf, R. Neggers, L. J. Donner, A. D. Del Genio, and Y. Liu, 2013: Evaluation of precipitation simulated by seven SCMs against the ARM observations at the SGP site. J. Climate, 26, 5467-5492, https://doi.org/10.1175/ JCLI-D-12-00263.1.

Song, J., K. Liao, R. L. Coulter, and B. M. Lesht, 2005: Climatology of the low-level jet at the Southern Great Plains Atmospheric Boundary Layer Experiments site. J. Appl. Meteor., 44, 1593-1606, https://doi.org/10.1175/JAM2294.1.

Stensrud, D. J., 1996: Importance of low-level jets to climate: A review. J. Climate, 9, 1698-1711, https://doi.org/10.1175/15200442(1996)009<1698:IOLLJT>2.0.CO;2.

Sun, W.-Y., and Y. Ogura, 1979: Boundary-layer forcing as a possible trigger to a squall-line formation. J. Atmos. Sci., 36, 235-254, https://doi.org/10.1175/1520-0469(1979)036< 0235:BLFAAP $>2.0 . \mathrm{CO} ; 2$.

Surcel, M., M. Berenguer, and I. Zawadzki, 2010: The diurnal cycle of precipitation from continental radar mosaics and numerical weather prediction models. Part I: Methodology and seasonal comparison. Mon. Wea. Rev., 138, 3084-3106, https://doi.org/ 10.1175/2010MWR3125.1.

Thorpe, A. J., and T. H. Guymer, 1977: The nocturnal jet. Quart. J. Roy. Meteor. Soc., 103, 633-653, https://doi.org/10.1002/ qj. 49710343809 .

Trier, S. B., and D. B. Parsons, 1993: Evolution of environmental conditions preceding the development of a nocturnal mesoscale convective complex. Mon. Wea. Rev., 121, 1078-1098, https://doi.org/10.1175/1520-0493(1993)121<1078: EOECPT>2.0.CO;2.

- C. A. Davis, D. A. Ahijevych, M. L. Weisman, and G. H. Bryan, 2006: Mechanisms supporting long-lived episodes of propagating nocturnal convection within a 7-day WRF model simulation. J. Atmos. Sci., 63, 2437-2461, https://doi.org/ 10.1175/JAS3768.1.

— — - and R. E. Carbone, 2014: Mechanisms governing the persistence and diurnal cycle of a heavy rainfall corridor. J. Atmos. Sci., 71, 4102-4126, https://doi.org/10.1175/JAS-D14-0134.1.

—, J. W. Wilson, D. A. Ahijevych, and R. A. Sobash, 2017: Mesoscale vertical motions near nocturnal convection initiation in PECAN. Mon. Wea. Rev., 145, 2919-2941, https://doi. org/10.1175/MWR-D-17-0005.1.

Tsuda, T., T. E. VanZandt, M. Mizumoto, S. Kato, and S. Fukao, 1991: Spectral analysis of temperature and Brunt-Väisälä frequency fluctuations observed by radiosondes. J. Geophys. Res., 96, 17 265-17 278, https://doi.org/10.1029/91JD01944.

Tuttle, J., and C. A. Davis, 2006: Corridors of warm-season precipitation in the central United States. Mon. Wea. Rev., 134, 2297-2317, https://doi.org/10.1175/MWR3188.1.

Uccelini, L. W., 1975: A case study of apparent gravity wave initiation of severe convective storms. Mon. Wea. Rev., 103, 497-513, https://doi.org/10.1175/1520-0493(1975)103<0497: ACSOAG $>2.0 . \mathrm{CO} ; 2$.

Van de Wiel, B. J. H., A. F. Moene, G. J. Steeneveld, P. Bass, F. C. Bosveld, and A. A. M. Holtslag, 2010: A conceptual view on 
inertial oscillations and nocturnal low-level jets. J. Atmos. Sci., 67, 2679-2689, https://doi.org/10.1175/2010JAS3289.1.

van Ulden, A. P., and A. A. M. Holtslag, 1985: Estimation of atmospheric boundary layer parameters for diffusion applications. J. Climate Appl. Meteor., 24, 1196-1207, https://doi.org/ 10.1175/1520-0450(1985)024<1196:EOABLP>2.0.CO;2.

Velasco, I., and J. M. Fritsch, 1987: Mesoscale convective complexes in the Americas. J. Geophys. Res., 92, 9591-9613, https://doi.org/10.1029/JD092iD08p09591.

Vermeesch, K., 2016: S-Pol site UMBC ceilometer (version 2). NCAR-UCAR Earth Observing Laboratory, accessed 25 April 2017, https://doi.org/10.5065/D6V122VT.

Wallace, J. M., 1975: Diurnal variations in precipitation and thunderstorm frequency over the conterminous United States. Mon. Wea. Rev., 103, 406-419, https://doi.org/10.1175/15200493(1975)103<0406:DVIPAT>2.0.CO;2.

Walters, C. K., and J. A. Winkler, 2001: Airflow configurations of warm season southerly low-level wind maxima in the Great Plains. Part I: Spatial and temporal characteristics and relationship to convection. Wea. Forecasting, 16, 513-530, https://doi.org/10.1175/1520-0434(2001)016<0513: ACOWSS $>2.0 . \mathrm{CO} ; 2$

Wang, D., Y. Zhang, and A. Huang, 2013: Climatic features of the south-westerly low-level jet over southeast China and its association with precipitation over east China. Asia-Pac. J. Atmos. Sci., 49, 259-270, https://doi.org/10.1007/s13143-0130025-y.

Weckwerth, T. M., and R. M. Wakimoto, 1992: The initiation and organization of convective cells atop a cold-air outflow boundary. Mon. Wea. Rev., 120, 2169-2187, https://doi.org/ 10.1175/1520-0493(1992)120,2169:TIAOOC.2.0.CO;2.

, and D. B. Parsons, 2006: A review of convection initiation and motivation for IHOP_2002. Mon. Wea. Rev., 134, 5-22, https://doi.org/10.1175/MWR3067.1.
- H. V. Murphey, C. Flamant, J. Goldstein, and C. R. Pettet, 2008: An observational study of convection initiation on 12 June 2002 during IHOP_2002. Mon. Wea. Rev., 136, 2283-2304, https://doi.org/10.1175/2007MWR2128.1.

Weiss, C. C., and H. B. Bluestein, 2002: Airborne pseudo-dualDoppler analysis of a dryline-outflow boundary intersection. Mon. Wea. Rev., 130, 1207-1226, https://doi.org/10.1175/15200493(2002)130<1207:APDDAO > 2.0.CO;2.

Whiteman, C. D., X. Bian, and S. Zhong, 1997: Low-level jet climatology from enhanced rawinsonde observations at a site in the southern Great Plains. J. Appl. Meteor., 36, 1363-1376, https://doi.org/10.1175/1520-0450(1997)036<1363: LLJCFE $>2.0 . C O ; 2$.

Wilson, J. W., and W. E. Schreiber, 1986: Initiation of convective storms at radar-observed boundary-layer convergence lines. Mon. Wea. Rev., 114, 2516-2536, https://doi.org/10.1175/15200493(1986)114<2516:IOCSAR >2.0.CO;2.

— , and R. D. Roberts, 2006: Summary of convective storm initiation and evolution during IHOP: Observational and modeling perspective. Mon. Wea. Rev., 134, 23-47, https://doi.org/ 10.1175/MWR3069.1.

Wingo, S. M., and K. R. Knupp, 2015: Multi-platform observations characterizing the afternoon-to-evening transition of the planetary boundary layer in northern Alabama, USA. Bound.Layer Meteor., 155, 29-53, https://doi.org/10.1007/s10546-0149988-1.

Yuan, W., J. Xu, Y. Wu, H. Chen, and J. Bian, 2010: Statistics of gravity wave spectra in the troposphere and lower stratosphere over Beijing. Sci. China Earth Sci., 53, 141-149, https:// doi.org/10.1007/s11430-010-0002-6.

Ziegler, C. L., and E. N. Rasmussen, 1998: The initiation of moist convection at the dryline: Forecasting issues from a case study perspective. Wea. Forecasting, 13, 1106-1131, https://doi.org/ 10.1175/1520-0434(1998)013<1106:TIOMCA > 2.0.CO;2. 